ISSN: 0213-2060

DOI: http://dx.doi.org/10.14201/shhme2015332550

\title{
AUTORES CAROLINGIOS EN LOS CÓDICES HISPANOS (SIGLOS IX-XI). UN ENSAYO DE INTERPRETACIÓN
}

\author{
Carolingian Authors in Hispanic Codex (9 $9^{\text {th }}-11^{\text {th }}$ Centuries). \\ An Essay of Interpretation
}

Fermín MIRANDA GARCÍA*

Depto. de Historia Antigua, Medieval, Paleografia y Diplomática. Facultad de Filosofía y Letras. Universidad Autónoma de Madrid. Campus de Cantoblanco. Cl Francisco Tomás y Valiente, 1. E-28049 MADRID. C. e.: fermin.miranda@uam.es

Recibido: 2015-04-06

Revisado: 2015-06-23

Aceptado: 2015-09-28

RESUMEN: El presente estudio pretende analizar la presencia de autores vinculados al denominado "renacimiento carolingio» en los manuscritos generados en los scriptoria hispanos de los siglos IX al XI, hasta los albores de la penetración de la reforma romana en que se detiene el análisis. Desde Alcuino a Hincmaro de Reims, sus obras se suceden en los manuscritos, aunque en calidad y densidad muy diversas, en función de temas (religiosos, cronísticos, literarios) y de espacios político-culturales (condados catalanes, Pamplona, Castilla, Léon). En ese análisis, se busca una aproximación a los objetivos perseguidos en la copia y a los impulsos ideológicos que pudieran existir tras ellos.

Palabras clave: Autores carolingios; Códices hispanos; Construcciones ideológicas.

ABSTRACT: This research aims to analyze the presence of authors linked to the so called "Carolingian Renaissance» in manuscripts generated in Hispanic scriptoria between $9^{\text {th }}$ and $11^{\text {th }}$ Centuries, until the origins of the Roman reform, where the analysis stops. From

* Orcid: 0000-0002-0072-8224.

Este estudio se enmarca en el proyecto HAR2012-32790 del Ministerio de Economía y Competitividad. 
Alcuin to Hincmar of Reims, their works keep showing up in the manuscripts, although very different in quality and density, depending on the topic (religious, chronicles, literary) and the politic-cultural spaces (Catalonia, Pamplona, Castile, Leon). This analysis seeks an approximation to the objectives pursued in those copies and to the ideological impulses that might have existed behind them.

Keywords: Carolingian Authors; Hispanic Manuscripts; Ideological Constructions.

SUMARIO: 0 Introducción. 1 Los autores y las obras. 2 Un ensayo de interpretación geopolítica. 3 Conclusiones. 4 Referencias bibliográficas.

\section{INTRODUCCIÓN}

Cuando el anónimo autor de la Crónica mozárabe del 754 narraba con todo el lujo de detalles de que era capaz la batalla de Poitiers, que enfrentó a las tropas de Carlos Martel, mayordomo de Austrasia, con el ejército de 'Abd al-Raḥmān al Gāfiqi, no dudaba en calificar a los ultrapirenaicos de europenses'. Tomaba prestada una identidad ya recogida a comienzos del siglo viI por Columbano de Bobbio y hecha suya, entre otros autores, por Beda en su Historia ecclesiastica gentis anglorum cien años más tarde ${ }^{2}$. Europa se constituía, sobre todo, en torno a la cristiandad latina, y el clérigo hispano podía así mantener intacto el espíritu de comunión que miraba, esperanzado e impaciente, hacia los francos vencedores del valí andalusí. Lo que interesa señalar aquí es la fluidez en el tráfico de ideas que recorría -que había recorrido al menos- el Occidente continental, desde Britania e Italia a Hispania ${ }^{3}$, y que parecía mantenerse todavía una generación después de la conquista omeya del reino godo. Bien es cierto que el mismo cronista manifestaba sin reparos su lamento por la desidia franca, que había impedido una derrota completa de los musulmanes; quizás vislumbraba ya un alejamiento de intereses que le resultaba claramente decepcionante.

Mil doscientos cincuenta años después, un grupo de expertos se reunió en Santiago de Compostela para tratar, precisamente, sobre la circulación de códices y escritos entre la Europa ultrapirenaica y la península Ibérica a partir de ese momento y hasta el siglo XIII ${ }^{4}$.

1 López Pereira, J. Eduardo (ed.). Crónica mozárabe de 754. Zaragoza: Anubar, 1980, \$80.

2 Las referencias de Columbano, en sus epístolas a Gregorio Magno (a. 600) y Bonifacio III (613-614) (Walker, G. S. M. Sancti Columbani Opera. Dublin: The Dublin Institute for Advanced Studies, 1957, pp. 2 y 36 [en línea: http://www.brepolis.net; consultado 30-11-2014]; BeDA. Historia ecclesiastica gentis anglorum, ed. latina y trad. al francés de André Crépin y otros, Paris: Éditions du Cerf, 2005 (existe una trad. española de Moralejo, José Luis, Madrid: Akal, 2013).

3 Por supuesto, también en sentido contrario, como mostró, por ejemplo, el coloquio de la Casa de Velázquez en 1990, publicado por Fontaine, Jacques y Pellistrandi, Christine (eds.). L'Europe héritière de l'Espagne wisigothique. Madrid: Casa de Velázquez, 1992.

4 Coloquio sobre circulación de códices y escritos entre Europa y la Península en los siglos VIII-XIII (1982. Santiago de Compostela). Santiago de Compostela: Universidad de Santiago de Compostela, 1988. En su ponencia Anscari Mundó se sorprendía por esa distinción geográfica (Europa/Península), presente en el título («Importación, exportación y expoliación de códices en Cataluña (siglos viII al XIII)», p. 87). 
Muy pocas de las interesantes aportaciones realizadas se centraban, sin embargo, en ese primer periodo coincidente, grosso modo, con el ascenso político-institucional de los carolingios y la reconstrucción del imperio en Occidente, y con la primera articulación de los reinos hispanocristianos, con el consecuente bagaje ideológico inherente a ambos procesos. Las posibles interrelaciones e influencias constituyen en sí mismas una cuestión de interés y complejidad evidentes, pero lo que aquí se pretende, de modo mucho más modesto, es situar el foco en un aspecto más concreto y, en cierto modo, simbólico de los muchos posibles en ese terreno: la presencia -o ausencia- de los autores del ámbito carolingio (lato sensu) entre los textos conocidos 5 , por conservados o documentados, que se copiaron y/o guardaron en las bibliotecas hispanas de la época, en un período que abrimos en torno al año 800 y que se cierra, de modo más o menos artificial, a mediados del siglo XI, cuando las influencias extrapeninsulares empiezan a situarse en otros ámbitos, camino ya de los impulsos generados por la reforma gregoriana.

El objetivo del análisis, obviamente, consiste, tras intentar establecer un elenco aproximado de autores, obras y talleres de producción, en intentar establecer en qué medida el testimonio hispano de esas obras permite seńalar su influencia, en el grado que corresponda, en la construcción de los imaginarios ideológicos de los diversos territorios o, por el contrario, hasta qué punto cabe deducir de su ausencia algún modo de resistencia a los modelos presentes en el mundo franco. La cuestión presenta la suficiente amplitud y complejidad como para plantear aquí, tan solo, una aproximación más o menos general que, sin duda, deberá ampliarse sobre terrenos, obras y tiempos más específicos, pero cuenta también con la suficiente base bibliográfica y documental para intentar un primer balance cuyos planteamientos e hipótesis, en muchos casos más que discutibles, deberán rectificarse con toda seguridad.

Por suerte, el exhaustivo estudio de los códices de esta época, que cabe remontar a los trabajos de Rudolf Beer sobre Ripoll y en el que debe mencionarse a especialistas del relieve de Agustín Millares Carlo y, sobre todo, Manuel C. Díaz y Díaz, permite tener un panorama bastante preciso del campo de análisis, aunque el acuerdo entre los investigadores no siempre resulte completo y se mantengan importantes problemas de datación y análisis. A sus obras cabe remitirse para las apreciaciones codicológicas y cronológicas que aquí se efectúen ${ }^{6}$.

5 Un extenso análisis del mundo intelectual carolingio en Rodríguez de la PeÑa, Manuel Alejandro. Los reyes sabios. Cultura y poder en la Antigüedad Tardía y Alta Edad Media. San Sebastián de los Reyes: Actas, 2008, en especial las pp. 399-764.

6 Sobre textos y casos concretos se harán las oportunas referencias en cada ocasión. Sirvan aquí tan solo, como ejemplo de la numerosa bibliografía, algunas de las obras más conocidas: BEER, Rudolf. «Los manuscrits del monastir de Santa María de Ripoll». Boletín de la Real Academia de Buenas Letras de Barcelona, 1909, vol. 9, pp. 137-170 y 1910, vol. 10, pp. 230-278, 299-320, 329-365 y 492-520 (1.a ed. en alemán, Viena, Akademie der Wissenschaften, 1907-1908); DíAZ y DíAZ, Manuel C. Códices visigóticos en la monarquía leonesa. León: Centro de Estudios e Investigación San Isidoro, 1983, y Libros y librerías en la Rioja altomedieval. Logroño: Instituto de Estudios Riojanos, $1991^{2}$ (1. a ed. 1979); Millares Carlo, Agustín. Corpus de códices visigóticos (ed. de M. C. Díaz, A. M. Mundó, J. M. Ruiz Asencio, B. Casado y E. Lecuona). Las Palmas de Gran Canaria: UNED, 1999, 2 vols. Un balance de conjunto en Barcenilla Mena, Ángel. «Las bibliotecas españolas de la Alta Edad Media». Perficit. Publicación de Estudios Clásicos. Textos y Estudios, 1994, vol. 18, pp. 89-121; 1996, vol. 20, pp. 3-86; y 1997, vol. 21, pp. 3-53, y 111-132. Especial interés 
FERMÍN MIRANDA GARCÍA

AUTORES CAROLINGIOS EN LOS CÓDICES HISPANOS (SIGLOS IX-XI).

UN ENSAYO DE INTERPRETACIÓN

Resultan bien conocidas, y debatidas en su intensidad y contenidos, las relaciones establecidas entre Carlomagno y Alfonso II de Asturias en las décadas últimas del siglo viII ${ }^{7}$. Más allá del valor y de la difícil interpretación que deba darse a los relatos cronísticos, sobre los que no cabe volver aquí, sí merece la pena recordar que en ese contexto se produce el contacto (¿?) epistolar entre los principales consejeros áulicos de ambos personajes, el anglosajón Alcuino de York, «nieto» intelectual muy directo de Beda, y Beato de Liébana. El motivo, el común y radical antiadopcionismo de ambos, cargado, aparte de su fidelidad a la ortodoxia, con motivos de política eclesiástica convergentes aunque distintos: el papel de la jerarquía mozárabe en la iglesia hispana, en el caso del segundo; la imprescindible unidad religiosa en la articulación ideológica del espacio carolingio, en el del primero ${ }^{8}$. Curiosamente, el testimonio diplomático de esta relación, una carta enviada por Alcuino a Beato como respuesta a los saludos que este le había hecho llegar a través de un peregrino peninsular a San Martín de Tours, no se conserva en ningún códice ni diploma del ámbito astur-leonés, sino copiado en una pieza riojano-pamplonesa ${ }^{9}$. Si se aceptan las diversas propuestas de fecha para la misiva, el año 799 e incluso el 800, el comentarista lebaniego del Apocalipsis habría fallecido muy poco después de leerla, o tal vez ni siquiera tuvo la oportunidad de hacerlo.

No es esta la única obra del monje anglosajón conservada en las bibliotecas hispanas o de la que se tiene noticia, aunque tampoco quepa considerarlo como un autor habitual en los escritorios al sur de los Pirineos. De hecho, la mayor parte proceden de San Millán de la Cogolla, donde se recogieron en tres volúmenes diferentes (aunque dos de ellas se conservan hoy unidas) y todas ellas en las décadas centrales del siglo x. Se trata, además de la carta a Beato, de un fragmento de la Vita sancti Martini Turonensis, una Retractatio metrica anónima, que parece inspirada en sus obras gramaticales, y parte

tiene la primera aproximación general, en un contexto más amplio, que efectuó DíAz y DíAz, Manuel C. «La circulation des manuscrits dans la Péninsule Ibérique du viII ${ }^{e}$ au XI ${ }^{e}$ siècle». Cahiers de Civilisation Médiévale, 1969, vol. 12, pp. 219-241 y 383-392. Sobre Cataluña, merece la pena el contexto al que se acerca Mundó, «Importación», pp. 87-134. Aunque la perspectiva de conjunto desborda ampliamente la cuestión, resultan de interés las páginas que le dedica Zimmermann, Michel. Écrire et lire à Catalogne (XI -XIt siècles). Madrid: Casa de Velázquez, 2003, en especial pp. 750-771.

7 Una aproximación en BronisCh, Alexander P. «Asturien und das Frankenreich zur Zeit Karls des Großen». Historisches Jahrbuch, 1999, vol. 119, pp. 1-40. También MuÑIz López, Iván. «Hacia una arqueología de la cultura. Patrones de movilidad intelectual entre Asturias y Francia (siglos V-XIII d. C.)». Revista de Literatura Medieval, 2013, vol. 25, pp. 165-194 y en especial 171-177.

8 No cabe aquí analizar la polémica ni su contexto histórico. Vid., a modo de balance de la cuestión y del debate historiográfico, OrLandis, José. «La circunstancia histórica del adopcionismo español», Scripta Theologica, 1994, vol. 26, pp. 1079-1091 [en línea: http://dadun.unav.edu/handle/10171/13142; consultado 2-12-2014].

9 Díaz, Códices, p. 114 (Archivo Histórico Nacional [AHN], ms. 1007B). Vaya por delante que las menciones codicológicas y diplomáticas que se efectúan en adelante no pretenden en modo alguno ser exhaustivas, sino tan solo dar una imagen cabal de conjunto a partir de la bibliografía consultada y de prospecciones en catálogos de algunos archivos y bibliotecas señeros. 
del tratado sobre la Trinidad (De fide Sanctae et Individuae Trinitatis), precisamente elaborado contra los adopcionistas ${ }^{10}$.

Con todo, la copia más singular se encuentra en el Libro de Horas de Fernando I (1055), cuyo prefacio sigue al De Psalmorum usu liber, al igual que había ocurrido dos siglos antes con el Libro de Horas de Carlos el Calvo, lo que ha llevado a apuntar una posible influencia de este último en la pieza leonesa. Para Manuel C. Díaz y Díaz, su principal estudioso desde el punto de vista codicológico, aunque el encargo de la obra corresponde a la reina Sancha, los artífices (el escriba Pedro y el miniaturista Fructuoso) procedían de tierras castellanas orientales o, más probablemente, riojano-pamplonesas, vinculadas a la corte real de Nájera ${ }^{11}$.

En ese marco de cohesión religiosa, que parece inspirar los contactos de Alcuino con las tierras hispanas, cabe situar un texto no identificado que se conserva en el Archivo Capitular de Burgo de Osma, pero procedente de un códice del siglo x cuya elaboración Manuel C. Díaz y Díaz pone en relación con el espacio pamplonés ${ }^{12}$. Se menciona porque su anónimo autor tenía presente, en su redacción, los cánones del concilio regional de Maguncia de 813, volcados a las cuestiones de la disciplina eclesiástica, y de modo especial la monástica. Como es bien sabido, esa había constituido, en la misma línea de acción, otra de las grandes preocupaciones de Alcuino (fallecido en 804) y del propio Carlomagno, pero no es posible situar el momento, temprano o tardío, en que esa información llegó a la península ni con qué motivo.

En relación con Alcuino y su influencia en los círculos ideológicos continentales debe ponerse a dos autores del mundo anglosajón de los que aquel bebe sin duda. Aunque anteriores a la etapa carolingia, su obra resultó de especial trascendencia en esos mismos ambientes y parece haber entrado en Hispania por las mismas vías. De Aldhelmo de Malmesbury (c 640-709) apenas se conserva la mención de sus epigramas (Aldhelelmi epigramatum opera) que hace Álvaro de Córdoba en la Vita Eulogii, como uno de los manuscritos que, procedente de San Zacarías (San Pedro de Siresa muy probablemente), llevó Eulogio a Córdoba a mediados del siglo $\mathrm{IX}^{\mathrm{I3}}$. En 927, un diploma del monasterio

10 De 933 es la copia de la Retractatio (AHN, ms. 1007B); de mediados del x la Vita y De Fide en RAH, cód. 13(1) y 13(3). Díaz, Rioja, 114, 134, 136 y 139; Millares, Corpus, 178, y Ruiz García, Elisa. Catálogo de la sección de códices de la Real Academia de la Historia. Madrid: Real Academia de la Historia, 1997, cód. 13, pp. 122 y 131.

11 Biblioteca Universitaria de Santiago, ms. 609 (Res. 1). Díaz, Códices, pp. 279-299 y en especial 292; Díaz y Díaz, Manuel C., Moralejo, Serafín, Pardo Gómez, M. ${ }^{a}$ Virtudes y García Piñeiro, M. ${ }^{a}$ Araceli (eds.). Libro de Horas de Fernando I de León. Santiago de Compostela: Xunta de Galicia, 1995, 2 vols.; Pardo Gómez, M. ${ }^{a}$ Virtudes. Catálogo de manuscritos da Biblioteca Xeral. Santiago de Compostela: Universidade de Santiago de Compostela, 1998, ms. 609, p. 117; Castiñeiras González, Manuel. «Libro de Horas de Fernando I y Sancha». En Valle Pérez, José Carlos (coord.). Enciclopedia del Románico en Galicia. A Coruña. Aguilar de Campoo: Fundación Santa María la Real, 2013, vol. 2, pp. 1143-1148.

12 Díaz, Códices, p. 363 (Archivo Catedral de Burgo de Osma [ACBO], ms. 90).

13 Álvaro de Córdoba. Sancti Eulogii vita vel passio, c. 9 y Eulogio de Córdoba. Epistula III (ad Wiliesindum). En Gil, Juan (ed.). Corpus Scriptorum Muzarabicorum. Madrid: CSIC, Instituto Antonio de Nebrija, 1973, vol. 1, pp. 335-336 y vol. 2, pp. 498-504. Pese a la identificación tradicional de San Zacarías con algún cenobio del entorno de Roncesvalles, parece más que probable que se trate de San Pedro de Siresa, fundación carolingia de c 830 cuyo primer abad se llamó, precisamente, Zacarías (Ubieto Arteta, Antonio. 
FERMÍN MIRANDA GARCÍA

AUTORES CAROLINGIOS EN LOS CÓDICES HISPANOS (SIGLOS IX-XI).

UN ENSAYO DE INTERPRETACIÓN

leonés de San Cosme y San Damián de Abellar menciona un libro de versos del mismo autor entre las obras donadas al cenobio con motivo de su fundación ${ }^{14}$. Puesto que el donante, el obispo Cixila, procedía quizás de Toledo, la sede episcopal para la que Eulogio fue electo antes de su muerte, y que varios de los libros mencionados por Álvaro coinciden con los donados por el prelado mozárabe, quizás se trate del mismo códice, o al menos ambos puedan ponerse en relación, aunque solo queda la referencia documental, por lo que no es posible establecer tal paralelismo ni a cuál de las varias obras versificadas del autor hacen referencia ${ }^{15}$.

El otro personaje anglosajón precarolino es, obviamente, Beda el Venerable. Su presencia en las bibliotecas hispanas de los siglos X-XI se extiende desde Ripoll ${ }^{16}$ y Montserrat en los condados catalanes a Cardeńa y Silos en la Castilla occidental, y no podía faltar en el escritorio emilianense ${ }^{17}$. De mediados del siglo $\mathrm{x}$ son las copias, procedentes de San Millán (c 947) y Cardeña (954), de De Coelo - una selección anónima elaborada a partir de sus obras sobre astronomía De temporum ratione y De natura rerum-, ambas relacionadas al parecer entre $\mathrm{si}^{18}$. De temporum ratione figura también en el inventario de la biblioteca del abad Oliva en Ripoll elaborado en 1047; se han conservado dos ejemplares parciales de ese tiempo procedentes de la desamortización de la abadía gerundense ${ }^{19}$; y también una temprana transcripción (siglo x) del De natura rerum que se ve acompañada en el mismo códice y cronología por De arte metrica, de la que se guarda además otra versión coetáne ${ }^{20}$. En aquel escritorio se habrían transcrito las Homiliae en la primera mitad del siglo xI, y en el mismo catálogo se recogen las Expositiones evangeliorum; ambas se han perdido, salvo que la primera pueda identificarse con el fragmento que se conserva en la Biblioteca de Montserrat ${ }^{21}$. Por último, entre los fondos del Archivo de la Corona

Historia de Aragón. 6. Origenes de Aragón. Zaragoza: Anubar, 1989, pp. 355-375; MarTín Duque, Ángel. «Del espejo ajeno a la memoria propia». En Martín Duque, Ángel (dir.). Signos de identidad histórica para Navarra. Pamplona: Caja de Ahorros de Navarra, 1996, p. 32).

14 BarCenilla, «Las bibliotecas», vol. 20, p. 31.

15 Una edición de su obra poética en Aldhelm, The Poetic Works (trad. al inglés de Lapidge, Michael y Rosier, James L.). London: Boydell \& Brewer, 1984.

${ }_{16}$ Además del trabajo de Beer, ya mencionado (n. 6), puede consultarse a modo de balance el estudio de Mundó, Anscari. «Lescriptori i la biblioteca de Ripoll des de la fundació fins el segle XI». En Obres completes. 1. Catalunya de la romanitat a la sobirania. Barcelona: Curial Edicions, 1998, pp. 434-437.

17 Aunque centra su estudio en la etapa posterior a 1076, Ruiz Asencio, José Manuel. «Códices pirenaicos y riojanos en la biblioteca de Silos en el siglo XI». En Fernández Flórez, José A. (dir.). Silos. Un milenio. Actas del Congreso Internacional sobre la Abadia de Santo Domingo de Silos. II. Historia. Santo Domingo de Silos: Universidad de Burgos-Abadía de Silos, 2003, pp. 177-210, analiza con detalle la intensa relación entre los escritorios de Silos y la Castilla occidental, en general, y San Millán, ya apuntada por otros autores como Díaz, Rioja, passim.

18 RAH, cód. 25(3) y 76. Millares, Corpus, n. ${ }^{\text {s }} 185$ y 209; Díaz, Códices, p. 321 y Rioja, pp. 120121 , señala las influencias que la copia de Cardeña tiene del escritorio emilianense.

19 Archivo de la Corona de Aragón [ACA], ms. Ripoll, 59 y 225. La primera de ellas parece seguir modelos italianos: Martínez Gázquez, José y Puigvert y Planaguma, Gemma. «Los excerpta de Beda (De temporum ratione, 19 y 23) en Ripoll (ACA, Ripoll 59 y Vat. reg. lat. 123)». Emerita. Revista de Lingüistica y Filología, 1996, vol. 62, pp. 295-305.

${ }_{20}$ ACA, Ripoll, ms. 46 (De arte metrica) y 106 (De natura rerum y De arte metrica).

21 Beer, «Ripoll», pp. 168, 271 y 272; Puig, Ignasi M. y Giner, M. Assumpta. Index codicològic del Viaje Literario de Jaume Villanueva. Barcelona: Institut d'Estudis Catalans, 1998, n. ${ }^{\circ} 479$, p. 96 . El fragmento 


$$
\begin{aligned}
& \text { FERMÍN MIRANDA GARCÍA } \\
& \text { AUTORES CAROLINGIOS EN LOS CÓDICES HISPANOS (SIGLOS IX-XI). } \\
& \text { UN ENSAYO DE INTERPRETACIÓN }
\end{aligned}
$$

de Aragón procedentes de Ripoll cabe señalar un De locis sanctis del siglo XI atribuido también a aquel $\mathrm{abad}^{22}$.

El único fragmento hispano -procedente de Silos y de origen último desconocidoque se conoce de la más famosa de sus obras, la ya mencionada Historia ecclesiastica gentis anglorum, presenta el título Vita Drictelmi monaci y sigue uno de sus capítulos $(5,12)$, aunque modificado y sin atribución de autoría, pero sus analistas lo consideran inspirado en modelos del norte del reino franco y elaborado en torno al año $1000^{23}$.

Coetáneo de Alcuino, y conocido sobre todo por su obra histórica, es Paulo Diácono. Sin embargo, no será la Historia Longobardorum el texto que llegue a la península hispánica, sino, en lógica con el tipo de trabajos más difundido, sus textos de carácter espiritual. A finales del x o comienzos del XI se copiaba la Vita sancti Gregorii Magni en San Millán y en algún lugar del oriente castellano ${ }^{24}$; y desde esas mismas fechas y durante toda la centuria siguiente tuvo cierto relieve en esas mismas comarcas riojanas y castellanas el Homiliarium, conservado en códices igualmente compilados y/o procedentes de San Millán ${ }^{25}$, Burgos y Valeránica ${ }^{26}$.

Las aportaciones en el terreno de la renovación monástica que habían promovido textos como los del concilio de Maguncia de 813, alcanzarán un impulso especial de la mano de los Commentaria in regulam sancti Benedicti de Esmaragdo de Saint-Mihiel ${ }^{27}$, activo impulsor, ya en el reinado de Luis el Piadoso, de la reforma benedictina diseñada por Benito de Aniano. Su trabajo sobre la regla benedictina tiene además un interés añadido, porque, dentro de la tradición didáctica que había inspirado a los círculos intelectuales carolingios desde la primera hora, intentó restituir el texto primitivo de Benito de Nursia con la corrección de los posibles errores de la tradición textual, a los que atribuía algunos de los problemas sobre la aplicación divergente de la norma en

de la Biblioteca de Montserrat [BM], ms. 792-I; Olıvar, Alexander. Catàleg dels manuscrits de la biblioteca del monestir de Montserrat. Montserrat: Monestir de Monserrat, 1977, n. ${ }^{\circ}$ 792, p. 187.

22 ACA, Ripoll, ms. 151.

23 BNF, nouv. acq. lat. 235. Millares, Corpus, p. 253; Díaz, Códices, p. 344. Una breve aproximación al personaje de Beda, su obra y su influencia en la introducción de J. L. Moralejo a su edición en español de la Historia eclesiastica, pp. 5-40 (vid. supra n. 2). La edición de la extensa obra de Beda en la Patrologia Latina de J. P. Migne, incluidas por tanto las obras aquí mencionadas, puede consultarse en línea [http://www.documentacatholicaomnia.eu/20_50_0627-0735-_Beda_Venerabilis,_Sanctus.html; consultado 1-12-2014].

24 RAH, cód. 13(2) y BNF, nouv. acq. lat. 235. Díaz, Rioja, pp. 133-140; Díaz, Códices, p. 344; Millares, Corpus, p. 178. Sobre la obra, Paolo Diacono, Vita sancti Gregorii Magni, ed. S. Tuzzo. Pisa: Centro di Cultura Medievale, 2002.

25 Museums Sheffield. Collection of The Gild of Saint Georges (Ruskin Collection), CGSG 03582; la ficha catalográfica sitúa el origen en San Millán a finales del siglo x [http://collections.museums-sheffield. org.uk; consultado 20-12-2014]. Díaz, Códices, p. 351 y Millares, Corpus, p. 273, atribuyen la procedencia del texto, de modo indeterminado, al entorno de Silos. Una edición clásica del Homiliario de Paulo Diácono en PL, 95, cols. 1159-1584.

26 ACB, ms.1 y Colegiata de Santillana del Mar, s/s. Díaz, Códices, p. 365; Millares, Corpus, pp. 26 y 177.

27 Una edición reciente de los Commentaria en Smaragde de Saint-Miniel. Commentaire du Prologue à la Règle de saint Benoît, eds. y trads. P. Engelbert, A. Spannegel y J.-É. Stroobant de Saint-Éloy. Paris: Éditions du Cerf, 2006. La clásica edición completa de sus obras en PL ha sido igualmente reimpresa (Smaragdi abbatis monasterii Sancti Michaelis Virdunensis opera omnia, ed. J. P. Migne. Turnouth: Brepols, 1997, PL 102). 
FERMÍN MIRANDA GARCÍA

AUTORES CAROLINGIOS EN LOS CÓDICES HISPANOS (SIGLOS IX-XI).

UN ENSAYO DE INTERPRETACIÓN

los diversos centros monásticos ${ }^{28}$. De su éxito da buena cuenta el importante número de copias conocido, incluidas las ibéricas, y lo temprano de algunas de estas. Solo en los espacios hispanocristianos (no existe constancia de su penetración en círculos mozárabes) se contabilizan, sin ánimo de exhaustividad, una docena de menciones y copias en muy diferente estado de conservación, y alguna de ellas podría remontarse, según sus analistas, a finales del siglo IX, apenas dos generaciones después de la muerte de su autor, y muy probablemente tomadas de textos ultrapirenaicos. Si las primeras referencias aparecen en ámbito catalán ${ }^{29}$, pamplonés o aragonés ${ }^{30} \mathrm{y}$, enseguida, en las tierras riojanas conquistadas, grosso modo, en el primer cuarto del siglo x (San Millán, Nájera) ${ }^{31}$, pronto se habrían extendido al ámbito castellano (Cardeña) ${ }^{32}$ e, incluso, aunque el testimonio resulta excepcional, a Galicia (San Julián de Caaveiro) ${ }^{33}$, donde consta en 936. Las versiones se suceden por tierras castellanas y pamplonesas hasta bien avanzado el siglo $\mathrm{XI}^{34}$.

No es esta la única obra de Esmaragdo que llegó a Hispania, aunque sí la más frecuente. Junto a los Commentaria, copiados en San Millán en 933, aparece la Via regia ${ }^{35}$; y las Collectiones in Epistulas et Evangelia se suceden en copias de Valeránica y Valvanera

28 Ponesse, Matthew D. «Smaragdus of St Mihiel and the Carolingian monastic reform». Revue Bénédictine, 2006, vol. 116, pp. 367-392; ÍDEM. «Editorial practice in Smaragdus of St Mihiel's commentary on the Rule of St Benedict». Early Medieval Europe, 2010, vol. 18, pp. 61-91.

29 En sendos testamentos de 908 y 915 y, ya de la segunda mitad del x, un fragmento en BM, ms. 7931 (procedente de San Benet del Bages). Zimmermann, Écrire, p. 758, identifica los «Esmaragdo» que figuran en esos diplomas con la Diadema Monachorum por su, dice, relativa abundancia en los escritorios hispanos, especialmente los riojanos; pero la mayor parte de las copias riojanas de Esmaragdo son de los Commentaria; Mundó, «Importación», p. 103; Olivar, Catàleg, n. 793, p. 189.

30 RAH, cód. 26. Díaz, Rioja, p. 218, lo fecha a finales del siglo ix y lo considera procedente del ámbito norteño, tal vez de Leire o del condado aragonés -lo que parece más probable-, aunque acabó pronto en San Millán.

31 En copias de comienzos del siglo x, hoy en Silos (Archivo del Monasterio de Silos [AMS], fr. 5-16), de 933 elaborada en San Millán (AHN, ms. 1007B) y de 976, en este caso adaptada al monasterio femenino de Santas Nunilo y Alodia de Nájera (RAH, cód. 62); Díaz, Rioja, pp. 30-31, 44-46 y 113-114. Para la versión de 976 de la RAH, vid. Ruiz Asencio, José Manuel. «Libellus a regula Sancti Benedicti Subtractus. Bibl. Academia de la Historia, Emilianensis, 62». En García Turza, Claudio (coord.). Los manuscritos visigóticos: Estudios paleográfico y codicológico. I. Códices riojanos datados. Logroño: Fundación San Millán de la Cogolla, 2002, pp. 175-200.

32 Del siglo $\mathrm{x}$, y del entorno castellano occidental, se conservan manuscritos procedentes o conservados en algún momento en las bibliotecas de San Pedro de Cardeña (elaborados en torno al año 900 -Rylands Library, ms. lat. 104- y al ańo 1000 -British Library [BL], add. ms. 30055-), Santo Domingo de Silos (año 945 -AMS, ms. 1-) y San Salvador de Oña (segunda mitad del siglo x -AHN, Clero 1024/30-); Millares, Corpus, n. ${ }^{\circ s}$ 108, 142 y 221; Díaz, Códices, pp. 336, 401, 411 y 468; Tyson, Moses. The Spanish manuscripts in the John Rylands Library. Manchester: Manchester University Press, 1932, p. 188. El monasterio de Valvanera conserva una copia de 954 cuya confección Díaz, Rioja, p. 89 y Millares, Corpus, n. ${ }^{\circ} 338$ sitúan en el cercano ámbito castellano.

33 Copia perdida mencionada en un diploma de esa fecha (BARCENILLA, «Las bibliotecas», vol. 20, p. 28).

34 Díaz, Códices, pp. 73 y 215; Millares, Corpus, n. ${ }^{\circ s} 175$ y 183, para textos procedentes de San Millán (Biblioteca Nacional [BN], ms. 18672) y Las Huelgas (s/s). BarCENILLA, «Las bibliotecas», vol. 20, p. 36 recoge una referencia en un inventario de Ońa en torno a 1200 que quizás se corresponda con la copia conservada en el AHN.

35 DíAz, Rioja, p. 114 (AHN, ms. 1007B). 


$$
\begin{aligned}
& \text { FERMÍN MIRANDA GARCÍA } \\
& \text { AUTORES CAROLINGIOS EN LOS CÓDICES HISPANOS (SIGLOS IX-XI). } \\
& \text { UN ENSAYO DE INTERPRETACIÓN }
\end{aligned}
$$

(mediados del siglo x), en el famoso Códice Rotense de finales del siglo x y aún en dos manuscritos más del siglo xi custodiados en la catedral de Burgos ${ }^{36}$. Por último, la Diadema monachorum, un manual de moral monástica, se había transcrito en Cardeña en algún momento del siglo $\mathrm{x}^{37}$.

Si casi todas las obras de Esmaragdo aquí mencionadas se han puesto en relación evidente con la introducción del monacato benedictino al sur de los Pirineos ${ }^{38}$, no deja de llamar la atención la presencia de la Via regia, una especie de «espejo de príncipes» que el autor habría dedicado en torno al año 810 a Carlomagno o, más probablemente, a su hijo Luis el Piadoso ${ }^{39}$.

Por el contrario, de la Concordia regularum, escrita por el primer impulsor de la reforma y maestro de Esmaragdo, Benito de Aniano, solo se conoce una copia elaborada en el siglo x en algún lugar no precisado de Cataluña y que se custodiaba en la abadía cisterciense de Santes Creus antes de la desamortización decimonónica ${ }^{40}$.

El mismo códice de San Millán, que en torno al año 900 recogía la Explanatio de Esmaragdo, incorporó también la obra atribuida a Defensor de Ligugé, el Libro de las centellas (Liber Scintillarum $)^{41}$, un clásico entre los textos que se difunden en la península hispánica procedentes del ámbito ultrapirenaico en esta etapa. Si bien el autor y su obra deben situarse en torno al ańo 700, su presencia en los scriptoria donde Esmaragdo resulta más frecuente permite vincularlo a las mismas corrientes de entrada. Manuscritos pamploneses, castellanos y leoneses recogen las acotaciones de Defensor sobre la Biblia y los Padres de la Iglesia (hasta Isidoro de Sevilla) ${ }^{42}$.

A la generación de Esmaragdo pertenece también uno de los emigrados hispanos con mayor relieve en los círculos carolingios, el obispo Claudio de Turín († c 828). Pese

36 Millares, Corpus, n. ${ }^{\text {os }} 39$ y 210; Díaz, Rioja, p. 95 y Códices, pp. 4 y 365 (Archivo Catedral Córdoba [ACC], ms. 1; Monasterio del Paular, s/s; RAH, cód. 78; ACB, ms. 1 y 2). Hasta donde se ha podido comprobar, Díaz, Rioja, pp. 32-42, en su desglose del contenido del Códice Rotense no menciona los Commentaria, que sí se recogen en la ficha catalográfica de la RAH (Ruiz, Catálogo, cód. 78, p. 402). Sobre el Esmaragdo de Valeránica, hoy en la catedral de Córdoba, vid. también, Étaix, Raymond. "Le "Smaragde" de Cordoue et autres manuscrits apparentés». Miscellània Litúrgica Catalana, 1990, vol. 4, pp. 13-27.

37 Millares, Corpus, n. 208 (RAH, cód. 75). Sobre la obra, Smaragdus of Saint-Miniel. The Crown of Monks, ed. y trad. D. Barry. Trappist (KY): Cistercian Publications, 2013.

38 Linage Conde, Antonio. Los orígenes del monacato benedictino en la Península Ibérica. León: Centro de Estudios e Investigación San Isidoro, 1973, vol. 2, pp. 794-801; DíAz, "La circulation», pp. $237-238$.

39 Bovendeert, Jasmijn. "Royal or monastic identity? Smaragdus'Via regia and Diadema monachorum reconsidered». En Corradini, Richard; Meens, Rob; Pössel, Christina y Shaw, Philip (eds.). Texts and Identities in the Early Middle Ages. Viena: Österreichischen Akademie der Wissenschaften, 2006, pp. 239-251.

40 Biblioteca Pública del Estado de Tarragona [BPET], ms. 69. Sobre Benito de Aniano y su reforma, vid. Grégorre, Réginald. «Benedetto di Aniane nella riforma monastica carolingia». Studi Medievali, 1985, s. 3, vol. 26, pp. 573-610. Una cuidada edición de la obra en Benedictus Anianensis. Concordia regularum, ed. P. Bonnerie. Turnhout: Brepols, 1992, 2 vols.

41 Defensor de Ligugé. Livre d'étincelles, ed. y trad. de H.-M. Rochais. Paris: Éditions du Cerf, 1961.

42 RAH, cód. 26 procedente de San Millán; BN, ms. 112 (León), 6.222 y 10.008 (ámbito castellano o riojano); Díaz, Códices, pp. 414 y 425 y Rioja, pp. 218-220; Millares, Corpus, n. ${ }^{\text {ss }} 186,260$ y 265. Sendos inventarios de Silos (c 1100) y Ońa (c 1200) hacen alusión a la presencia del texto en sus bibliotecas (BARCENILLA, «Las bibliotecas», vol. 20, pp. 36 y 47). 
FERMÍN MIRANDA GARCÍA

AUTORES CAROLINGIOS EN LOS CÓDICES HISPANOS (SIGLOS IX-XI).

UN ENSAYO DE INTERPRETACIÓN

a sus orígenes y a su visión antiadopcionista, muy cercana a la de Beato de Liébana ${ }^{43}$, sus obras, sobre todo comentarios bíblicos, apenas traspasaron el Pirineo, a tenor de las escasas referencias encontradas. El inventario de Ripoll de 1047 menciona un genérico Claudius, del que no se tiene mayor noticia, aunque cabe deducir que se trata de un texto de ese tenor por el lugar que ocupa en el listado ${ }^{44}$, y que no es posible poner con seguridad en relación con sus Commentaria in Genesim copiados en el mismo siglo Ix en un manuscrito tal vez procedente de Urgell ${ }^{45}$.

Amalario de Metz († 850) fue discípulo de Alcuino y autor, en la línea renovadora de su maestro y de otros autores ya señalados, de los De Ecclesiasticis officiis libri quatuor, un tratado dedicado a Luis el Piadoso sobre el valor y sentido de los rituales litúrgicos ${ }^{46}$ del que se habían elaborado copias en Ripoll en la primera mitad del siglo xI. De la misma época se conserva un manuscrito procedente de los fondos desamortizados a Santes Creus, aunque no pueda establecerse un posible nexo entre ellos ${ }^{47}$.

Discípulos de Alcuino, siquiera por breve tiempo, fueron también Haymo de Halberstadt $(\dagger 851)$ y Rabano Mauro ( $\$ 856)$. Del primero, menos conocido, autor de comentarios bíblicos, como muchos de los autores aquí mencionados, llegó a Hispania su Expositio in Apocalipsim, copiada en un códice del siglo XI que acabó en Santes Creus ${ }^{48}$. Con el segundo, sin duda uno de los personajes más relevantes de su generación ${ }^{49}$, la nómina se amplía, aunque limitada, hasta donde es posible conocer, a textos teológicos. El mismo testamento de 915 que mencionaba a Esmaragdo hace referencia inconcreta a Rabano Mauro ${ }^{50}$; su comentario sobre el Libro de los Números (Enarrationes in librum Numerorum) se había copiado hacia 960 en el oriente castellano o el entorno de San Millán ${ }^{51}$. Hacia el año 1000 se habían incluido sus Homiliae en un manuscrito de Silos ${ }^{52}$, y figuraba, sin obra concreta, en el inventario de Ripoll, con las obras depositadas en Monserrat ${ }^{53}$.

43 Cavadini, John. «Claudius of Turin and the Agustinian Tradition». En Pulsiano, Philip (ed.). Proceedings of the PMR Conference. Villanova: Villanova University, 1986, pp. 43-50.

44 BEER, «Ripoll», p. 271.

45 BNF, lat. 9575. Millares, Corpus, n. ${ }^{\circ}$ 250. Sobre esta obra y su relieve, Gorman, Michael. «The Commentary on Genesis of Claudius of Turin and Biblical Studies under Louis the Pious». Speculum, 1997, vol. 72, pp. 279-329.

46 Chazelle, Celia. «Amalarius's Liber officialis: spirit and vision in Carolingian liturgical thought». En Nie, Giselle de; Morrison, Karl Frederick y Mostert, Marco (eds.). Seeing the Invisible in Late Antiquity and the Early Middle Ages. Turnhout: Brepols, 2005, pp. 327-357 [DOI: 10.1484/M.USML-EB.3.2353].

47 Biblioteca de Catalunya, ms. 944 [probablemente un facticio recompuesto a comienzos del XII]; el ejemplar procedente de Santes Creus en BPET, ms. 85. BeER, «Ripoll», p. 266; Zimmermann, Écrire, pp. 760-761.

48 BPET, ms. 149. La obra fue editada en la PL, 117, cols. 937-1220.

49 Depreux, Philippe y otros (eds.). Raban Maur et son temps. Turnhout: Brepols, 2005 [en línea: http://brepols.metapress.com/content/j8968t/?sortorder=asc; consultado 15-01-2015]

50 Zimmermann, Écrire, p. 758.

51 Instituto Valencia de don Juan, 26.IV.36. AndrÉs, Gregorio de. «Un nuevo fragmento visigótico del siglo x de un comentario bíblico de Hrabano Mauro». Revista de Archivos, Bibliotecas y Museos, 1979, vol. 82, pp. 855-859. Una edición de las Enarrationes en PL, 108, cols. 538-838.

52 BNF, nouv. acq. lat. 235. Díaz, Códices, p. 344; Millares, Corpus, n. ${ }^{\circ}$ 263. Las Homiliae se editaron en $P L, 110$, cols. 9-468.

53 Beer, «Ripoll», p. 276. Zimmermann, Écrire, p. 758, sugiere que se pudiera tratar de su famoso De laude Sanctae Crucis («porquoi pas?»). 


$$
\begin{aligned}
& \text { FERMÍN MIRANDA GARCÍA } \\
& \text { AUTORES CAROLINGIOS EN LOS CÓDICES HISPANOS (SIGLOS IX-XI). } \\
& \text { UN ENSAYO DE INTERPRETACIÓN }
\end{aligned}
$$

Entre los principales teólogos del tiempo de Luis el Piadoso se encuentra Pascasio Radberto († 851), cuyas polémicas con otros autores, como el propio Rabano Mauro, resultan bien conocidas ${ }^{54}$. Cogitis me, un documento sobre la Asunción de María de atribución discutida, pero previsiblemente suyo, figura en un manuscrito del siglo x que con posterioridad se añadió a un códice facticio; no es posible establecer su origen más allá de saber que procede de algún territorio hispanocristiano y no del espacio mozárabe al que corresponde el resto del códice ${ }^{55}$. Del siglo XI es una copia catalana del mismo texto, recogido junto a un homiliario de Beda, entre otras obras ${ }^{56}$. Mejor localizada, aunque tampoco con precisión, su obra más original, De corpore et sanguine Domini, se incluyó en torno al año 1000 en el mismo manuscrito de Silos donde aparecen las Homilias de Rabano Mauro ${ }^{57}$. In Lamentationes Jeremiae consta en un códice de Ripoll, hoy perdido, que sus glosadores sitúan en la primera mitad del $\mathrm{XI}^{58}$.

La hagiografía constituyó el principal interés de Aimoino de Saint-Germain-des-Près, cuyo nombre, sin más referencia, aparece en el inventario de Ripoll de 1047. Por su colocación en el listado, entre los libros «espirituales», parece que el Aimoinis que figura se refiere a aquel autor, de mediados del siglo ix, y no, como quería Rudolf Beer, al autor de la Historia Francorum, Aimoino de Fleury, que vivió a finales del siglo x y comienzos del $\mathrm{XI}^{5}{ }^{9}$. Cabe recordar, además, que Aimoino de Saint-Germain compuso el relato sobre el traslado de las reliquias de los mártires mozárabes Jorge, Aurelio y Natalia desde Córdoba hasta su abadía en torno a 871, aunque no pueda saberse si era este el relato que recogía el códice perdido de Ripoll ${ }^{60}$. Por añadidura, uno de los monjes protagonistas del traslado, compañero de Aimoino en Saint-Germain y también hagiógrafo, Usuardo, es autor de una poco conocida Grammatica, que le dedicó, y que se añadió, dedicatoria incluida, a otro de los volúmenes rivipulienses, en este caso conservado todavía y fechado en el siglo $\mathrm{x}^{61}$.

Como ya se apuntaba a propósito de Paulo Diácono, la historiografía carolingia permanece casi ágrafa en los scriptoria hispanos. La excepción, nada sorprendente, es Ripoll, donde se habría copiado en la primera mitad del siglo xI un fragmento de la Vita

54 Otтen, Willemien. «Carolingian theology». En Evans, G. R. (ed.). The medieval teologians. An Introduction to Theology in the Medieval Period. Oxford: Blackwell, 2000, pp. 65-82, analiza de modo singular las disputas eucarísticas entre ambos.

55 ACC, ms. 123. Millares, Corpus, n. 40.

56 BM, ms. 792-IX. Olivar, Catàleg, n. ${ }^{\circ}$ 792, p. 189.

57 BNF, nouv. acq. lat. 235. Díaz, Códices, p. 344; Millares, Corpus, n. o 40. Aunque desde una perspectiva más amplia, para el interés de la obra vid. Appleby, David. «Beautiful on the Cross, Beautiful in His Torments. The Place of the Body in the Thought of Paschasius Radbertus». Traditio, 2005, vol. 60, pp. 1-46 [DOI: $10.1353 /$ trd.2005.0005].

58 BeER, «Ripoll», p. 266, que sigue a Villanueva, Jaime. Viage literario a las Iglesias de España. Madrid: Real Academia de la Historia, 1806-1807, vol. 8, pp. 36-37 [en línea: Biblioteca Digital Hispánica, http://bdh-rd.bne.es/viewer.vm?id=0000010216\&page=1; consultado 30-10-2014]; ZimmermanN, Écrire, p. 759. La obra en PL, 111, cols. 793-1272.

59 BEER, «Ripoll», p. 271.

60 LaRa Olmo, Juan Carlos. «El relato del traslado de los santos mártires Jorge, Aurelio y Natalia: un valioso escrito hagiográfico y documental histórico de mediados del siglo IX». Hispania Sacra, 1999, vol. 51, pp. 55-89 [en línea: http://search.proquest.com/docview/1302625039?accountid=14478; consultado 21-11-2014].

61 ACA, Ripoll, 46. BeER, «Ripoll», p. 246. Sobre el autor y la obra, Zimmermann, Écrire, pp. 759-760. 
FERMÍN MIRANDA GARCÍA

AUTORES CAROLINGIOS EN LOS CÓDICES HISPANOS (SIGLOS IX-XI).

UN ENSAYO DE INTERPRETACIÓN

Karoli de Eginardo, cuya correspondencia se desconoce, pero que figura en el inventario de 1047 y, todavía, en el que realizó, a comienzos del siglo xIX, Jaime Villanueva en su Viage Literario. En el mismo códice se habría copiado un texto muy vinculado a aquella obra, los Versus in Einhardi Vitam Karoli, del bibliotecario de Luis el Piadoso Gerwardo, al que Eginardo tal vez dedicó la biografía ${ }^{62}$.

Como resulta conocido, otros autores acompañaron a Eginardo en su otra gran obra histórica, los Annales regni francorum en sus diversas variantes y continuaciones. Los de nombre conocido, Prudencio de Troyes e Hincmaro de Reims, en sucesivas generaciones de historiadores hasta el tercer cuarto del siglo IX, también constan en los códices hispanos, pero en ningún caso en esa faceta. Del hispano Prudencio (Galindo) se conservan cuatro referencias a su más famoso trabajo vinculado a los estudios bíblicos, las Flores Psalmorum, presentes ya en 933 en San Millán ${ }^{63}$; figuraba además en manuscritos de fecha indeterminada, hoy desaparecidos, de Ońa, Poblet y San Juan de las Abadesas ${ }^{64}$.

Su sucesor $-\mathrm{y}$ rival- al frente de los $A R F$, Hincmaro de Reims, aparece tan solo en Ripoll, en una copia efectuada en torno a 1020 de dos de sus cartas, dentro de un amplio lote de diplomas regios francos que incluye, por ejemplo, las capitulares de Carlomagno y Luis el Piadoso recopiladas por Ansegiso en 828 y el juramento prestado por el rey Eudes (Promissio Odonis regis) en su proclamación del año $888^{65}$.

Curiosamente, Ermoldo Nigelo ( $\dagger$ c 830), autor del Carmen in honorem Hludovici imperatoris que narra con detalle, entre otras cuestiones, la conquista de Barcelona en 801, no consta en las bibliotecas catalanas, ni su referencia más conocida aparece reflejada en la península. Pero sí se encuentra otro de sus poemas, los Versus ad pueros, una breve admonición sobre la educación de los niños de la familia regis que dedicó a Pipino I de Aquitania -hijo de Luis el Piadoso- del que fue consejero. La obra se transcribió en San Millán en el año 964, y es al parecer la única conocida de este texto ${ }^{66}$. Otro carmen de la primera mitad del siglo Ix, en este caso el dedicado por Floro de Lyon († c 860) a su contemporáneo el abad Eldrado de Novalesa ${ }^{67}$, figura en el Libro de Horas de Fernando I junto a los comentarios a los Salmos de Alcuino a los que se ha hecho referencia.

La generación que vio la crisis última del modelo imperial carolingio, la de finales del siglo Ix, limita su presencia peninsular a un par de autores y al espacio catalán en

62 Beer, «Ripoll», pp. 168 y 266; Villanueva, Viage literario, vol. 8, pp. 36-37. Noble, Thomas F. X. Charlemagne and Louis the Pious. The Lives by Einhard, Notker, Ernoldus, Thegan and the Astronomer. University Park: Pennsylvania State Press, 2009, pp. 11-13.

63 AHN, cód. 1006B y 1007B. Díaz, Rioja, p. 178; Millares, Corpus, n. ${ }^{\text {os }} 126$ y 127.

64 En los casos de Ońa y Poblet figuraban en inventarios de finales del siglo xiı; en el caso de San Juan, se trata de un inventario de 1874 (BArCenilla, "Las bibliotecas», vol. 20, p. 37 y 4, pp. 119 y 127). Una edición de las Flores como Breviarium Psalterii en PL, 115, cols. 1449-1458.

65 ACA, ms. Ripoll, 40. BeER, «Ripoll», pp. 266 y 272; Bernadó, Màrius. «Códice misceláneo». En Zapke, Susana (ed.). Hispania vetus. Manuscritos litúrgicos-musicales. De los orígenes a la transición francorromana: siglos IX-XII. Bilbao: Fundación BBVA, 2007, p. 318.

${ }_{66}$ RAH, cód. 46. Díaz, Rioja, p. 145, apunta a la posibilidad de que un códice procedente de Silos, del que se conservan solo fragmentos, fuera copia de este y contuviese también el texto (BNF, nouv. acq. lat. 1296). La obra fue editada por DümmLer, Ernst en los MGH. Poetae latini aevi Carolini. II, Berlin: Weimann, 1884, pp. 92-93.

67 Dümmler, MGH. Poetae, II, pp. 549-550. 


$$
\begin{aligned}
& \text { FERMÍN MIRANDA GARCÍA } \\
& \text { AUTORES CAROLINGIOS EN LOS CÓDICES HISPANOS (SIGLOS IX-XI). } \\
& \text { UN ENSAYO DE INTERPRETACIÓN }
\end{aligned}
$$

exclusiva, aunque se copiaron de forma temprana. Las Homiliae de Luculentio se incorporaron a la biblioteca de San Cugat en algún momento del siglo $\mathrm{x}^{68}$; y a comienzos del xi la reputada obra musical de Hucbaldo de Saint-Amand se había introducido en Ripoll, donde se recogió el Liber de armonica institutione dentro de un códice dedicado precisamente a la enseñanza musical ${ }^{69}$.

\section{2}

\section{UN ENSAYO DE INTERPRETACIÓN GEOPOLÍTICA}

No parece necesario detenerse in extenso en la presencia de autores carolingios en el ámbito pluricondal catalán. Aparte de que diversos y exhaustivos análisis ya efectuados eximen en buena medida de ello ${ }^{70}$, la conquista carolingia de la "Cataluña Vieja» en los años finales del siglo viıI y primeros del IX introdujo estos territorios, bien que geográficamente periféricos, en un espacio institucional e ideológico del que los autores del «renacimiento carolingio» constituían parte esencial. La reforma de la regla benedictina propuesta por Benito de Aniano, continuada por sus discípulos como Esmaragdo de Saint-Mihiel e introducida en los cenobios de todo el Imperio, y la renovación eclesiástica que se gestionó en paralelo -y con anterioridad- tuvo aquí su lógica repercusión en forma también de importación de los textos más habituales, y no solo en las abadías de mayor relieve, como Cuxá, Ripoll o Montserrat, sino, como se encargó de señalar Anscari Mundó, en catedrales y pequeños centros igualmente influidos por el proceso ${ }^{71}$. Además de las numerosas piezas conservadas, inventarios como el famoso de Ripoll, elaborado a la muerte del abad Oliva, manifiestan la intensidad de la penetración de estos nuevos valores a través de la interpretación religiosa, hagiográfica o eclesiástica de, por supuesto, los propios Benito de Aniano y Esmaragdo, pero también de Claudio de Turín, Prudencio de Troyes, Aimoino de Saint-Germain, Luculentio o Haymo de Halberstadt. No faltaron las obras vinculadas a la nueva liturgia, como las de Amalario de Metz o, en el terreno musical, Hucbaldo; ni, por supuesto, las obras enciclopédicas, no necesariamente de temática religiosa, de Beda.

Mayor incertidumbre presenta interpretar el porqué de conservar, en manuscritos del siglo XI, piezas que recordaban con intensidad la vinculación jurídica de los condados con el imperio/reino franco, en fechas en las que la aparente distancia de los condes catalanes con el nuevo orden surgido de la «revolución» capeta de 987 se habría consumado ampliamente. La Vita Karoli de Eginardo, las recopilaciones de capitulares de Ansegiso, copias sueltas de diplomas regios o dirigidos a los monarcas -como las de Hincmaro a Carlos el Calvo-, el propio juramento de Eudes en 888 -primer símbolo de la ruptura de la legitimidad carolingia, siquiera intermitente, por parte de los «robertianos»-,

68 RAH, cód. 17 y 21; Mundó, Anscari M. «Entorn de dos codex del segle $x^{e ̀ ~ d e ~ S a n ~ C u g a t ~ d e l ~ V a-~}$ llès». Faventia, 1982, vol. 4, n. ${ }^{\circ}$ 2, pp. 7-24.

69 ACA, Ripoll, 42; BeER, «Ripoll», p. 266; Bernadó, «Musica cum rethorica», p. 348.

70 Mundó, «Importación», pp. 87-137; Zimmermann, Écrire, en especial pp. 750-771, entre otras posibles citas.

71 Mundó, «Importación», pp. 98-105. 
FERMÍN MIRANDA GARCÍA

AUTORES CAROLINGIOS EN LOS CÓDICES HISPANOS (SIGLOS IX-XI).

UN ENSAYO DE INTERPRETACIÓN

se copiaban pocos años después en códices casi de modo específico pensados para guardar semejante memoria.

¿Se trataba de crear un argumentario justificativo para una situación de crisis "constitucional» que habría abocado a esa independencia de «facto» tan querida para buena parte de la historiografía? O, por el contrario, ¿se pretendía mantener en su plenitud el marco jurídico en el que los espacios condales se consideraban encuadrados al margen de la ilegitimidad de que se acusaba a la nueva dinastía? Si, como afirman los especialistas, esas copias deben ponerse en el haber de la etapa abacial de Oliva en Ripoll, en torno a 1020, la consideración de que semejantes acciones contienen una importante carga ideológica no parece que deba desdeñarse ${ }^{72}$.

Otra cosa es la posible interpretación que pueda darse en ese segundo caso. Si bien la colaboración entre Oliva, él mismo miembro conspicuo de la alta aristocracia laica hasta su toma de hábito, y después abad y obispo, con las familias condales de la región resultó de singular intensidad, no es menos cierto que marcó siempre un proyecto de independencia eclesiástica frente a los poderes laicos, pero también de intromisión en la gestión civil del territorio. No cabe, pues, descartar que ese tipo de recopilaciones tuvieran como objetivo crear una línea de defensa jurídica mediante el recuerdo permanente del marco en que unos y otros se movían, basado en un modelo de soberanía franca que se mantendría pese a todo. Cuánto hubiera de aceptación de esos presupuestos - en el caso de que lo fueran- por parte de las autoridades condales, parece de improbable comprobación. Resultaría necesario quizás un análisis detallado, aquí imposible, del contenido concreto de esas recopilaciones y copias para ver las posibilidades de establecer puntos de partida en ese terreno ${ }^{73}$.

En el camino hacia Occidente, el monasterio aragonés de Siresa, con el que con casi total seguridad debe identificarse el «San Zacarías» que mencionaba Eulogio a mediados del siglo IX cuando intentaba pasar a territorio franco, supone no solo un vínculo con los territorios catalanes, sino también directo con las tierras aquitanas. El condado de Aragón permanecía en ese momento, y hasta bien entrado el siglo x, en la órbita carolingia tras su conquista paralela a la de los espacios más orientales del Pirineo. Desde esa perspectiva, y aunque no se trate de un autor especialmente habitual, la presencia del anglosajón Aldhelmo de Malmesbury entre sus fondos no se adivina tan extraña. La historiografía ha considerado de modo habitual que Eulogio volvió a al-Ándalus con el códice allí guardado, y ha visto en ello una cierta desidia cultural de los monjes pirenaicos frente al afán de conocimiento del clérigo, lo que casa mal con las loas que dedica al abad Odoario (summae sanctitatis magnaeque scientia vir), a la comunidad monástica (quod famosissimis in exercitatione regularis disciplinae studiis decoratum toto refulgebat occiduo), a

72 Sobre este personaje y su contextualización pueden verse las numerosas referencias que le dedican, en los tomos VII** y IX de la Historia de España Menéndez Pidal, SaLrach, Josep M. ${ }^{a}$. «El régimen político condal», VII**, pp. 575-612; RIu, Manuel. «La organización eclesiástica», VII**, pp. 613-648 y «La vida cultural», pp. 699-725; y Udina, Federico. "Cataluña», IX, pp. 425-402.

73 En una breve aproximación que ha podido efectuarse a la Collectio Capitularia de Ansegiso en su versión on-line de Brepols (www.brepolis.net; consultado 15-12-2014), según la edición de MGH Capit. 1 (1883) pp. 394-450, solo ha podido encontrarse una referencia a Hispania, a propósito de la convocatoria de hueste (1.3, c. 74), lo que en sí mismo no resulta especialmente significativo. 


$$
\begin{aligned}
& \text { FERMÍN MIRANDA GARCÍA } \\
& \text { AUTORES CAROLINGIOS EN LOS CÓDICES HISPANOS (SIGLOS IX-XI). } \\
& \text { UN ENSAYO DE INTERPRETACIÓN }
\end{aligned}
$$

su dedicación al estudio (studebant cuncti silentio; colloquium de divinis scripturis gerentes) y con la propia riqueza de su biblioteca sobre la que insiste también su biógrafo Álvaro (multa volumina librorum repperiens abstrusa et pene a multis remota hic remeans) ${ }^{74}$. Sin embargo, sería conveniente apuntar la posibilidad de otras hipótesis, relacionadas con el propio sistema de intercambios librarios propio del momento: pudo tratarse de una copia efectuada sobre un manuscrito sirense $o$, tal vez, un préstamo que, debido a la propia trayectoria vital de Eulogio, nunca se devolvió -y Álvaro revistió de regalo-, tal y como ocurrirá, en un sentido y en otro, con otros muchos códices destinados a la copia en monasterios cercanos o remotos ${ }^{75}$. Se ha discutido igualmente la vinculación de este cenobio con la regla benedictina en fechas tan tempranas ${ }^{76}$. Sin embargo, la propia mención a san Benito (pero no a otros santos vinculados a las reglas hispanas más habituales) en el primer diploma que se conserva, de $828-832^{77}$, y la posibilidad de que el «Esmaragdo» más antiguo que nos ha llegado, de la segunda mitad del Ix, proceda de este ámbito y se le atribuyan influencias librarias ultrapirenaicas, parece mostrar claros indicios en ese sentido, que guardan cierta lógica, por otra parte, con el propio marco institucional del condado en este momento.

Siresa se conformaría así como puente directo de contacto cultural entre el mundo aquitano, el pirenaico-occidental $\mathrm{y}$, tras la conquista de principios del siglo $\mathrm{x}$ (e incluso con anterioridad), el riojano; pero también con los espacios catalanes con los que, como demuestran los textos genealógicos de finales del siglo $\mathrm{x}$, las relaciones familiares a lo largo de toda la cordillera resultan muy fluidas desde tiempo atrás, tal vez al menos desde la efímera conquista de Pamplona por Luis el Piadoso en torno al $812^{78}$.

Uno y otro camino habrían alimentado a San Millán de la Cogolla y su amplio área de influencia. Se trata, sin duda, de la abadía hispana que, como se ha visto en el relato previo, mayor concentración de obras de autores carolingios consiguió establecer,

74 Así, Goñi Gaztambide, José. Los obispos de Pamplona. I. Siglos IV-XIII. Pamplona: Eunsa-Gobierno de Navarra, 1979, pp. 67-73. Por el contrario, Durán Gudiol, Antonio. «Francos, pamploneses y mozárabes en la Marca Superior de al-Ándalus». En SÉnAc, Philippe (dir.). La Marche Superieur d'al-Andalus et l'Occident chrétien. Madrid: Casa de Velázquez, 1991, p. 142, hace precisamente hincapié en el espíritu de estudio que loa Eulogio. Las citas siguen la edición de la Vita Eulogii y la Epistola ad Wiliesindum de GiL, Corpus, pp. 335 y 498-499.

75 El propio Coloquio sobre circulación de códices ya citado (n. 4), y especialmente las ponencias de Aires Augusto Nascimento, Anscari M. Mundó, José Mattoso o Manuel C. Díaz y Díaz ofrecen diversas propuestas al respecto. Además, DíAz, «La circulation», passim.

76 Linaje, Orígenes, I, pp. 455-457, considera que, de haber sido así, Eulogio habría hecho alguna mención al contraste con lo habitual hasta entonces en el mundo hispánico.

77 Ubieto Arteta, Antonio. Cartulario de Siresa. Valencia: Anubar, 1960, n. ${ }^{\circ}$ 1. El códice 26 de la RAH, guardado en San Millán desde fecha indeterminada, pero cuyo origen DíAz, Rioja, p. 218, sitúa en el Pirineo pamplonés o aragonés.

78 Vid. las páginas que dedica Juan José Larrea a la posible conformación de una diócesis en Aragón en relación con el condado carolingio en "Obispos efímeros, comunidades y homicidio en la Rioja Alta en los siglos x y XI». Brocar, 2007, vol. 31, pp. 179-181, y al "efímero episodio carolingio» en "Construir un reino en la periferia de Al-Ándalus: Pamplona y el Pirineo Occidental en los siglos viII y IX». Territorio, Sociedad y Poder, 2009, Anejo 2, pp. 287-288. También, Miranda García, Fermín. "Carlomagno, los carolingios y la creación de la Marca Hispánica». En Peña González, José y Rodríguez de la Peña, Manuel Alejandro (eds.). Carlomagno y la civilización carolingia. Madrid: CEU Ediciones, 2014, pp. 165-194. 
FERMÍN MIRANDA GARCÍA

AUTORES CAROLINGIOS EN LOS CÓDICES HISPANOS (SIGLOS IX-XI).

UN ENSAYO DE INTERPRETACIÓN

excepción quizás del caso de Ripoll, en función de la documentación y los ejemplares conservados. Por supuesto, la mayor parte de ellos constituye un núcleo de textos vinculados a la reforma eclesiástica y a la interpretación teológica y litúrgica que le acompanó, como resultaba habitual. Suponen con todo un claro exponente de la temprana influencia -en relación con los espacios políticos más orientales- que tuvieron los modelos ultrapirenaicos, lo que no deja de contrastar con la resistencia que, en la segunda mitad del siglo XI, las autoridades políticas y eclesiásticas pamplonesas manifestaron hacia las reformas impulsadas desde Roma y en defensa del ritual hispánico tradicional ${ }^{79}$. Los Commentaria y otras obras exegéticas de Esmaragdo se repiten (aparte de la copia del siglo Ix final que se acaba de mencionar) desde muy tempranas fechas del $\mathrm{x}$ y hasta entrado el xi en los códices emilianenses o de otros centros riojanos. Pero no faltan otros tratados en el mismo campo como Defensor de Ligugé, la hagiografía de san Gregorio obra de Paulo Diácono, o las exégesis del Libro de los Números de Rabano Mauro y del Libro de los Salmos de Prudencio Galindo, el obispo de más que probable origen aragonés, en su Flores Psalmorum.

Cabe, sin embargo, detenerse con cierto detalle en diversos autores y obras cuya presencia en el entorno de San Millán de la Cogolla puede tener otro interés, no necesariamente alejado de la cuestión religiosa pero con posibles implicaciones en el campo de la ideología política. En el escritorio emilianense se habían copiado en la primera mitad del siglo $\mathrm{x}$ varios textos de Alcuino, entre ellos la carta que dirigió a Beato de Liébana en la que animaba a la lucha contra el adopcionismo, acompañada de un texto teológico en el mismo campo de combate (De fide sanctae et individuae Trinitatis), la Vita Sacti Martini y una pequeña obra gramatical que, aunque no le es atribuible, parece inspirada en sus trabajos. Pero además, en esas mismas fechas se copiaban, junto a textos enciclopédicos inspirados en Beda ( $D e$ Coelo), dos obras que presentan a un tiempo una incuestionable carga didáctica y política, destinadas en su origen al círculo regio. Se trata de la Via regia del mismo Esmaragdo, diseñada con casi total seguridad para la educación de Luis el Piadoso, y los Versus ad pueros de Ermoldo Nigelo, dirigidos a la familia de Pipino I de Aquitania, hijo de aquel. Son piezas todas ellas que se transcriben entre 933 y 963 , en coincidencia por tanto con el complicado inicio efectivo del reinado de García I (925-970), recién salido en esas fechas de una minoría oficial -tenía 12 ańos en 931- que se prolongó en el tiempo bajo la influencia de su madre, Toda. ¿¿Se copiaron en San Millán con algún objetivo similar? La estrecha relación del monasterio con la familia real pamplonesa, bien estudiada, invita a una respuesta afirmativa ${ }^{80}$. La presencia en el mismo códice que la Via regia de la Retractatio metrica, inspirada en las obras sobre gramática de Alcuino, ayuda a dar cohesión al manuscrito y al conjunto de textos en ese terreno «docente», del que la carga ideológica que contienen parece inseparable.

79 Goñı, Historia, p. 219; Martín Duque, Ángel. «El despliegue del reino de Aragón y Pamplona (1076-1134)». En Historia de España Menéndez Pidal. IX. Madrid: Espasa-Calpe, 1998, pp. 271 y 313.

80 Martín Duque, Ángel. «El reino de Pamplona». En Historia de España Menéndez Pidal. VII. La España de los siglos VIII al XI. II. Los núcleos pirenaicos (718-1035). Navarra, Aragón, Cataluña. Madrid: EspasaCalpe, 1999, pp. 249-250. 


\author{
FERMÍN MIRANDA GARCÍA \\ AUTORES CAROLINGIOS EN LOS CÓDICES HISPANOS (SIGLOS IX-XI). \\ UN ENSAYO DE INTERPRETACIÓN
}

Puesto que la abuela del joven rey, madre de Sancho I y, por tanto, suegra de Toda, era Dadildis de Pallars (cuya fecha de muerte es desconocida), cabría el atrevimiento de apelar al relieve de las mujeres de la familia regis en la educación de los hijos a la hora de buscar influencias de esas tierras orientales en los modelos escogidos, y en todo caso a la fluidez de relaciones que ese matrimonio suponía. Pero quizás tenga mayor sentido pensar en la incorporación del condado de Aragón al reino de Pamplona, en los años últimos del reinado de Sancho I (905-925), y con él de los depósitos monásticos y nobiliarios de la herencia cultural carolingia, como Siresa o la propia familia condal. El compromiso primero (919) y el matrimonio después (c 935) - pronto disuelto por consanguinidad- entre la heredera del condado, Andregoto, y el rey García señalan en esa dirección. Que el inicio del reinado en teoría efectivo, aunque tutelado en la práctica por Toda, de García I (931) y la copia de la Via regia de Esmaragdo (933) y de alguno de los textos de Alcuino coincidan en el tiempo, no deja de parecer algo más que una curiosa casualidad. Que esos textos se prolonguen hasta los ańos 60, casi hasta el final de un reinado instalado en la zozobra permanente debido a la presión de las razias califales de 'Abd al-Raḥmān III, llama igualmente la atención.

En una hipótesis de difícil, cuando no imposible, confirmación cabría por tanto interpretar que el escritorio emilianense en las décadas centrales del siglo $\mathrm{x}$, que coinciden grosso modo con el reinado de García I, habría articulado un bagaje de textos procedentes del mundo carolingio destinados a dar una cierta cohesión al modelo ideológico del reino en un contexto de crisis. La unidad religioso-ideológica que ofrecían textos como el tratado de Alcuino sobre la Trinidad (el mayor símbolo de la idolatría cristiana para los musulmanes) podría ser un buen apoyo a los textos didácticos que, quizás, suponen la parte más importante de este posible "corpus».

Sin embargo, los grandes códices articulados en el reinado de Sancho II (970-994) ofrecen una imagen distinta sobre la que parece necesario llamar la atención. El Códice Albeldense y el Códice Emilianense ${ }^{81}$, este último obviamente articulado en el mismo San Millán, carecen de textos procedentes del mundo carolingio en particular y ultrapirenaico en general. Se ha llamado reiteradamente la atención sobre el intenso espíritu neogoticista que les impregna, también puesto en relación con la parte del linaje regio vinculada a Ramiro de Viguera, hijo de García I y su segunda esposa, Teresa de León -hija de Ramiro II-. En ese contexto de juegos de poder y de giros en el modelo ideológico San Millán habría caído bajo su influencia, y quizás esa situación explique el cambio -siempre relativo- del programa impulsado desde el monasterio ${ }^{82}$.

Pero los textos carolingios vuelven en torno al año $1000^{83}$ al Códice Rotense (RAH, cód. 78), del que se ha señalado también el mayor contacto de sus contenidos con el

81 Biblioteca del monasterio de San Lorenzo del Escorial, d.I.2 (Albeldense) y d.I.1 (Emilianense); DíAz, Rioja, pp. 63-71 y 155-162.

82 Miranda García, Fermín. «La imagen del poder monárquico en el reino de Pamplona (siglo x)». En VI Congreso General de Historia de Navarra. Navarra: memoria e imagen. III. Ponencias. Pamplona: Ed. Eunate, 2007, pp. 73-95.

83 La fecha de cierre se ha discutido ampliamente. Lacarra, José María. «Textos navarros del Códice de Roda». Estudios de Edad Media de la Corona de Aragón, 1945, vol. 1, pp. 196-198, apunta hacia el año 992, en coincidencia por tanto con el del Emilianense. Díaz, Rioja, p. 34, y Ruız, Catálogo, p. 395, prefieren fijar la fecha a principios del XI. 
mundo ultrapirenaico y, además, con los propios espacios de la cordillera con los que se habían anudado relaciones tiempo atrás. Sin marcar un posible regreso a los orígenes, el Rotense copia las Collectiones in Epistolas et Evangelia de Esmaragdo, y los códices de San Millán del siglo XI retomarán al autor; aunque Alcuino no está presente, sí figuran en el mismo Rotense textos sobre la Trinidad (Agustín, Isidoro de Sevilla) y formularios de profesiones de fe sobre la cuestión que parecen inspirados en aquel ${ }^{84}$.

Además, la genealogía que incorpora de los reyes francos, y que se detiene en Lotario (†986), ignora a los robertianos, salvo Eudes, hasta el punto de señalar que entre Carlos III el Simple (893-922) y Luis IV de Ultramar (936-954), fuimus (sic) sine rege ${ }^{85}$; la inspiración procarolingia del texto, fuera cual fuese la procedencia, parece evidente. Nada significativo en sí mismo, pero quizás tenga su interés en el conjunto del diseño del códice, tal vez elaborado unos pocos años después que el Emilianense en el propio ámbito de la corte najerense, manifestando así una cierta divergencia entre los diversos círculos de poder en la articulación ideológica del reino.

Esa «renovada» lente carolingia, por influida que pudiera estar de las reminiscencias neogoticistas de los años 970-990, ayudaría a contextualizar las relaciones establecidas por Sancho III (999-1035) con el abad Oliva de Ripoll a partir de los años 1020. En el breve epistolario conservado, Oliva, además de dictar una serie de consejos -en línea con actitudes habituales en el prelado, ya comentadas-, alaba de modo especial las virtudes del monarca pamplonés y le proclama retóricamente como rex Ibericus $^{86}$. Parece tratarse de una imagen de supremacía moral que podía oponerse en cierto modo al vacío de la ilegitimidad capeta, aunque con toda probabilidad dentro de la conciencia de que la seguridad jurídica debía resolverse en otro ámbito como insinúa la copia de las capitulares carolingias que se está produciendo a instancia sin duda del mismo Oliva. Pero desde el punto de vista pamplonés, acompañada de los contactos que también se mantuvieron con Cluny, el intercambio supone una proyección hacia los espacios ideológicos continentales que difícilmente puede suponerse surgida ex novo si se consideran todos los antecedentes.

Los textos carolingios habían llegado igualmente a los escritorios monásticos del oriente de Castilla, pero no parece que en este caso quepa intuir una especial carga político-ideológica, si bien no debe olvidarse la fluidez de una frontera sobre la que tanto los monarcas pamploneses como los reyes leoneses, y en especial sus condes castellanos, pretendían ampliar sus espacios de control ${ }^{87}$. Los especialistas insisten en que casi todos estos manuscritos se organizan bajo el importante peso de la influencia del scriptorium de

84 RAH, 78, fols. 212 a 230.

85 LACARra, «Textos navarros», p. 254.

86 Martín Duque, Ángel. Sancho III el Mayor de Pamplona. El rey y su reino (1004-1035). Pamplona: Gobierno de Navarra, 2007, pp. 265-269. Las cartas de Oliva a Sancho III en Jimeno, Roldán y Pescador, Aitor. Colección documental de Sancho Garcés III, el Mayor, rey de Pamplona (1004-1035). Pamplona: Pamiela, 2003, n. ${ }^{\text {os }} 29$ (1023) y 67 (c 1030-1032).

87 Vid. a título de ejemplo las breves notas que dedica a esta cuestión Miranda García, Fermín. «Monarquía y espacios de poder político en el reino de Pamplona (1000-1035)». En XXX Semana de Estudios Medievales de Estella'03. Ante el milenario del reinado de Sancho el Mayor. Un rey navarro para España y Europa. Pamplona: Gobierno de Navarra, 2004, pp. 43-70. 


$$
\begin{aligned}
& \text { FERMÍN MIRANDA GARCÍA } \\
& \text { AUTORES CAROLINGIOS EN LOS CÓDICES HISPANOS (SIGLOS IX-XI). } \\
& \text { UN ENSAYO DE INTERPRETACIÓN }
\end{aligned}
$$

San Millán ${ }^{88}$, pero, sobre todo, los autores y obras que se conocen procedentes de Cardeña, Silos, Oña, Burgos o Valeránica se centran en aspectos vinculados a las cuestiones eclesiológicas y, en general, teológicas, desde los Commentaria a la regla de san Benito y la Diadema monachorum de Esmaragdo, en el terreno de la reforma benedictina, a las obras hagiográficas de Beda o Paulo Diácono o los Homiliaria o estudios exegéticos de los mismos Beda, Paulo Diácono y Esmaragdo, junto a Defensor de Ligugé, Pascasio Radberto y, como dato más singular, Rabano Mauro.

Evidentemente, existe en todos ellos una carga de adecuación religiosa, no necesariamente opuesta a los modelos hispánicos, con los que conviven -en minoría- en las bibliotecas monásticas, pero que manifiesta una cierta apertura a otros horizontes, siquiera influida por la propia personalidad y relieve de los escritorios riojanos reiteradamente mencionados. No cabe desdeńar, antes al contrario, que los condes castellanos, que mantuvieron una permanente relación con San Millán, cuya activa presencia dominial en esas comarcas resulta bien conocida ${ }^{89}$, vieran en el impulso de esta abadía una fuente de renovación exportable a sus cenobios, ni que estos siguieran su estela de modo autónomo, sin necesidad de influencias del poder político. Pero no parece intuirse en esa labor de copia un interés por modelos políticos vinculados al desarrollo del poder monárquico que, por otro lado, poco podían interesar a las familias condales castellanas, cuya relación de dependencia con la monarquía leonesa no resultaba habitualmente fluida. Los argumentarios de los autores carolingios no por ajenos -aunque tal vez solo en parte- a los idearios neogoticistas dejaban de suponer una intensa defensa del imaginario monárquico ${ }^{90}$.

Precisamente, el avance de la mirada hacia el Occidente leonés depara en la práctica un desierto librario en lo que al mundo carolingio respecta. Apenas cuatro menciones localizadas en todo el arco temporal acotado, y algunas de ellas con serios problemas de procedencia, cuando se conocen más de 700 referencias documentales y códices conservados para el conjunto de la monarquía entre los siglos viII al XI ${ }^{91}$. La presión de los rituales, liturgia y modelos heredados de la tradición hispanogoda parece infranqueable. Así, la referencia a una copia de los «Versos» de Aldhelmo de Malmesbury que se donó al monasterio de Abellar en 927, pero que por su donante, el obispo mozárabe

88 Así, Díaz, Códices, o Ruiz Asencio, «Códices pirenaicos», passim.

89 García de Cortázar y Ruiz de Aguirre, José Ángel. El dominio del monasterio de San Millán de la Cogolla (siglos $X$ al XIII). Introducción a la historia rural de Castilla altomedieval. Salamanca: Universidad de Salamanca, 1969. Interesan también las reflexiones que sobre esta cuestión el mismo autor efectuó años más tarde: «El dominio del monasterio de San Millán de la Cogolla en los siglos x al XiI». En Cordero RiverA, Juan (coord.). San Millán de la Cogolla. Logrońo: Ateneo Riojano, 1999, pp. 13-26, y que inciden de modo especial en esta cuestión.

90 Sobre las construcciones ideológicas de la monarquía leonesa cabe señalar, entre la amplia bibliografía, algunos trabajos de conjunto de indudable interés, como Deswarthe, Thomas. De la destruction à la restauration: L'idéologie du royaume d'Oviedo-Leon (VIII-XI siècles). Turnhout: Brepols, 2003, y SiranTOINE, Hélène. Imperator Hispanie. Les idéologies impériales dans le royaume de Léon (IXe-XII siècles). Madrid: Casa de Velázquez, 2012. En relación con el incuestionable depósito de carga religiosa que tiene esta construcción del poder y el papel de la Iglesia, Ayala Martínez, Carlos de. Sacerdocio y reino en la España altomedieval. Iglesia y poder político en el Occidente peninsular, siglos VII-XII. Madrid: Sílex, 2010.

91 Díaz, Códices, pp. 178-190. 
FERMÍN MIRANDA GARCÍA

AUTORES CAROLINGIOS EN LOS CÓDICES HISPANOS (SIGLOS IX-XI).

UN ENSAYO DE INTERPRETACIÓN

Cixila, bien pudo tener su origen en el ámbito andalusí al que, dos generaciones antes, Eulogio había llevado esos mismos epigramas del autor anglosajón desde Siresa. Menos discusión tiene la temprana copia de los Commentaria de Esmaragdo, que se encontraba en San Julián de Caaveiro en el 936, o el Liber Scintillarum de Defensor de Ligugé, transcrito en fecha y lugar indeterminados del siglo xi leonés. La propia naturaleza de los textos, los más habituales del repertorio, no permiten especiales hipótesis ni interpretaciones de calado.

Pero un último códice, sin duda uno de los de mayor relieve de esta época, introduce un paisaje singular. Se trata del llamado Libro de Horas de Fernando I y Sancha, elaborado en 1055 y conocido también como Diurno de Fernando I. Como se ha indicado más arriba, el códice incluye en su prefacio parte del estudio de Alcuino sobre los Salmos (De Psalmorum usu liber), tal y como ocurría, por otra parte, en otro Libro de Horas, el de Carlos el Calvo ${ }^{92}$, del que habría tomado ejemplo, y también el poema que Floro de Lyon dedicó al abad Eldrado de Novalesa, un conjunto de virtudes heroicas perfectamente aplicables al destinatario del códice. Un modelo carolingio, con textos, entre otros, del más conspicuo de los intelectuales de Carlomagno de la primera hora, para articular un texto al servicio de la piedad de un rey de León. El encargo corresponde, según señala el propio códice, a la reina Sancha, la hermana del difunto Bermudo III, cuyo matrimonio con Fernando elevó a este hijo de Sancho III y conde de Castilla desde 1029 al trono de León en 1037. Y el encargo se produjo un año después tan solo de que la derrota y muerte de García III de Pamplona en Atapuerca, enfrentado precisamente a Fernando, situase a este como cabeza del linaje pamplonés, ante la minoría de Sancho IV en Pamplona y la condición ilegítima del príncipe aragonés Ramiro. Parece constituir, por tanto, un homenaje a la gloria del personaje, situado en la cima de su prestigio.

¿Buscó la reina los modelos en los que inspirar la obra? ¿Fueron una propuesta del rey, sin duda al tanto del encargo? ¿Se trató de una decisión de los artífices del manuscrito, sus escribas y miniaturistas? ¿ $\mathrm{O}$ un conjunto de todo ello? Si se considera el vacío previo de obras carolingias en el reino de León, parecería que la primera posibilidad resultaba lejana, si no fuera porque el texto indica de modo expreso que el libro se hizo de acuerdo con la voluntad de la reina, y su imagen y nombre se hace presente de modo reiterado. De hecho, se ha apuntado que el manuscrito constituye todo un símbolo del peso de Sancha en el rearme de un «imperialismo» leonés al que dotaría de legitimidad como transmisora del linaje regio ${ }^{93}$. Pero Fernando, sin embargo, se había educado en la corte najerense, en ese entorno donde el Códice Rotense manifestaba todavía el relativo -o no tan relativo- poso de la herencia intelectual ultrapirenaica. Los expertos apuntan además que los modelos

92 Sobre la composición del códice y sus influencias se sigue la bibliografía indicada en la nota 11, y en especial el balance crítico de CastiñeIras, "El libro de Horas».

93 Castiñeiras, "Libro de Horas», p. 1144. Acerca del relieve de Sancha en el programa ideológico de Fernando I, vid. Sirantoine, Imperator Hispaniae, pp. 142-163. Ruiz García, Elisa. "Arma regis. Los libros de Fernando I y dońa Sancha». Lemir. Revista de Literatura Española Medieval y del Renacimiento, 2014, vol. 18, pp. 137-176 y en especial 146-150, ha inisitido sobre el relieve de la producción de esta obra en el conjunto librario de la pareja y en su programa ideológico, aunque siempre desde la óptica «neogiticista». 


$$
\begin{aligned}
& \text { FERMÍN MIRANDA GARCÍA } \\
& \text { AUTORES CAROLINGIOS EN LOS CÓDICES HISPANOS (SIGLOS IX-XI). } \\
& \text { UN ENSAYO DE INTERPRETACIÓN }
\end{aligned}
$$

librarios parecen inspirarse en el mundo emilianense ${ }^{94}$, al que los condes castellanos (y Fernando lo había sido) y sus abadías se habían sentido tan cercanos; y entre los artífices conocidos de la obra figura un Fructuoso, pictor, cuyo nombre se corresponde con un escriba de la corte de Nájera documentado en los ańos cuarenta y principios de los cincuenta del siglo XI y con otro - ¿o el mismo?- de Fernando I en $1063^{95}$. También en algún diploma de Nájera de este momento se han apreciado similitudes con las miniaturas del Libro de Horas de Fernando $I^{96}$. Manuel C. Díaz y Díaz atribuye además un origen castellano oriental o incluso najerense al escriba principal, Pedro, de acuerdo con su estilo de escritura ${ }^{97}$.

En el conjunto de este complicado ejercicio, podría apuntarse, por tanto, que al evidente interés de Sancha por representar el relieve de la pareja en su momento de mayor esplendor, que cabría calificar, con los matices que corresponda, de «imperial hispano» -al menos en grado de pretensión-, se sumó el poso de unos modelos ideológicos, si no alternativos al menos complementarios, de «imperialismo universal» carolingio. No es posible establecer cuán conscientes eran, mediado el siglo xI, el propio Fernando o esos escribanos tal vez procedentes de un reino en plena crisis, el de Pamplona, del relieve que ese modelo había tenido en todo el arco pirenaico, desde Cataluña a La Rioja, pero sin duda servía ampliamente para reforzar los patrones que interesaba señalar.

\section{Conclusiones}

La desigual penetración de los autores carolingios a lo largo de los territorios hispanocristianos permite, con todo, dibujar algunos perfiles de cierto interés. Por supuesto, una temática, la eclesiástico-religiosa, y un espacio, el de los condados precatalanes, alcanzan el mayor protagonismo. La reforma religiosa vinculada a la renovación benedictina, la exégesis bíblica y los homiliarios destinados a la educación de los clérigos suponen

94 Díaz, Códices, pp. 178-190; Silva y Verástegui, Soledad de. «La imagen miniada». En Bango Tonviso, Isidro (ed.). La edad de un reyno. Sancho el Mayor y sus herederos. Pamplona: Fundación para la Conservación del Patrimonio Histórico de Navarra, 2006, pp. 409-411, en relación al Psalterio de mediados del siglo XI (AHN, ms. 1006B) al que en algún momento se incorporaron varios folios de las Flores Psalmorum de Prudencio de Troyes copiados en el siglo x y procedentes de AHN, ms. 1007B. Estudio con reproducción de imágenes en Gaite Pastor, Jesús y Sáenz Pascual, Raquel. «Psalterio y Libro de Cánticos». En Bango Torviso, La edad de un reyno, pp. 128-129.

95 Cantera Montenegro, Margarita. Colección documental de Santa Maria la Real de Nájera (siglos X-XIV). San Sebastián: Sociedad de Estudios Vascos, 1991, n. ${ }^{\text {os }} 7$ (1044) y 8 (1046); Ubieto Arteta, Antonio. Cartulario de San Millán de la Cogolla (759-1076). Valencia: Anubar, 1976, n. 285; Blanco Lozano, Pilar. Colección diplomática de Fernando I (1037-1065). León: Centro de Estudios e Investigación San Isidoro, 1987 , p. 25 y n.o 118 (1063).

96 Silva y Verástegui, «La imagen miniada», p. 411, y Galván Fraile, Fernando. «Documento de fundación del monasterio de Santa María de Nájera». En Bango Torviso, La edad de un reyno, pp. 287-290, quien discute que el diploma miniado corresponda a mediados de siglo, pero considera que el original debió de incluir también algún tipo de miniatura semejante.

97 No ha sido posible localizar a este Pedro en la documentación riojana de la época, y solo en dos ocasiones, en un diploma falsificado que pretende remontarse a 1042 y en otro de 1061, aparece con ese nombre un notario entre los diplomas de Fernando I (Blanco Lozano, Colección de Fernando I, p. 25 y n. ${ }^{\text {os }} 14$ (1042) y $113(1061)$ 
FERMÍN MIRANDA GARCÍA

AUTORES CAROLINGIOS EN LOS CÓDICES HISPANOS (SIGLOS IX-XI).

UN ENSAYO DE INTERPRETACIÓN

la mayor y mejor parte de las copias, mientras que la vinculación política, jurídica y cultural del Pirineo oriental al imperio/reino franco sitúa los escritorios de esta zona en el mismo marco y modelo de desarrollo que los continentales de la misma órbita. Un modelo que se mantuvo, incluso, tras la ruptura capeta y el rechazo de la aristocracia catalana hacia el nuevo orden constituido.

Pero la intensidad que alcanza ese conjunto de obras en espacios más occidentales, sobre todo en el ámbito riojano vinculado al reino de Pamplona, permite intuir además una conexión ideológica singular que poner en relación no solo con las redes eclesiásticas y familiares del espacio de la cordillera pirenaica, sino también, de modo directo, con el mundo transpirenaico que tuvo, a comienzos del siglo IX, una presencia política directa en el ámbito pamplonés.

Por contra, los espacios leoneses, incluida Castilla, presentan una situación muy diferente. Aunque el ámbito oriental castellano, muy relacionado con el mundo monástico riojano, no duda en inspirarse en él a la hora de adquirir ciertas referencias religiosas dominantes, el conjunto aparenta un amplio desdén hacia influencias ajenas al ámbito peninsular. Solo la llegada de la dinastía pamplonesa al trono de León de la mano de Fernando I permite matizar el aserto, pero las consecuencias de esa desigual confluencia corresponden ya a otro sujeto de estudio.

\section{REFERENCIAS BIBLIOGRÁFICAS}

Aldhelm. The Poetic Works (trad. al inglés de Lapidge, Michael y Rosier, James L.). London: Boydell \& Brewer, 1984.

ANDrÉs, Gregorio de. «Un nuevo fragmento visigótico del siglo x de un comentario bíblico de Hrabano Mauro». Revista de Archivos, Bibliotecas y Museos, 1979, vol. 82, pp. 855-859.

Appleby, David. «Beautiful on the Cross, Beautiful in His Torments. The Place of the Body in the Thought of Paschasius Radbertus». Traditio, 2005, vol. 60, pp. 1-46.

Ayala Martínez, Carlos de. Sacerdocio y reino en la España altomedieval. Iglesia y poder politico en el Occidente peninsular, siglos VII-XII. Madrid: Sílex, 2010.

Barcenilla Mena, Ángel. «Las bibliotecas españolas de la Alta Edad Media». Perficit. Publicación de Estudios Clásicos. Textos y Estudios, 1994, vol. 18, pp. 89-121; 1996, vol. 20, pp. 3-86; y 1997, vol. 21, pp. 3-53, y 111-132.

Beda. Historia ecclesiastica gentis anglorum, ed. latina y trad. al francés de André Crépin y otros, Paris: Éditions du Cerf, 2005.

BeEr, Rudolf. «Los manuscrits del monastir de Santa María de Ripoll». Boletín de la Real Academia de Buenas Letras de Barcelona, 1909, vol. 9, pp. 137-170 y 1910, vol. 10, pp. 230-278, 299-320, 329-365 y 492-520.

Benedictus Anianensis. Concordia regularum, ed. P. Bonnerie. Turnhout: Brepols, 1992, 2 vols.

Blanco Lozano, Pilar. Colección diplomática de Fernando I (1037-1065). León: Centro de Estudios e Investigación San Isidoro, 1987.

BovendeERT, Jasmijn. «Royal or monastic identity? Smaragdus'Via regia and Diadema monachorum reconsidered». En Corradini, Richard; Meens, Rob; Pössel, Christina y Shaw, Philip (eds.). Texts and Identities in the Early Middle Ages. Viena: Österreichischen Akademie der Wissenschaften, 2006, pp. 239-251. 


$$
\begin{aligned}
& \text { FERMÍN MIRANDA GARCÍA } \\
& \text { AUTORES CAROLINGIOS EN LOS CÓDICES HISPANOS (SIGLOS IX-XI). } \\
& \text { UN ENSAYO DE INTERPRETACIÓN }
\end{aligned}
$$

Bronisch, Alexander P. «Asturien und das Frankenreich zur Zeit Karls des Großen». Historisches Jahrbuch, 1999, vol. 119, pp. 1-40.

Cantera Montenegro, Margarita. Colección documental de Santa María la Real de Nájera (siglos X-XIV). San Sebastián: Sociedad de Estudios Vascos, 1991.

Castiñeiras González, Manuel. «Libro de Horas de Fernando I y Sancha». En Valle Pérez, José Carlos (coord.). Enciclopedia del Románico en Galicia. A Coruña. Aguilar de Campoo: Fundación Santa María la Real, 2013, vol. 2, pp. 1143-1148.

Cavadini, John. "Claudius of Turin and the Agustinian Tradition». En Pulsiano, Philip (ed.). Proceedings of the PMR Conference. Villanova: Villanova University, 1986, pp. 43-50.

Chazelle, Celia. "Amalarius's Liber officialis: spirit and vision in Carolingian liturgical thought». En Nie, Giselle de; Morrison, Karl Frederick y Mostert, Marco (eds.). Seeing the Invisible in Late Antiquity and the Early Middle Ages. Turnhout: Brepols, 2005, pp. 327-357.

Defensor de Ligugé. Livre d'étincelles, ed. y trad. de H.-M. Rochais. Paris: Éditions du Cerf, 1961.

Depreux, Philippe y otros (eds.). Raban Maur et son temps. Turnhout: Brepols, 2005.

Deswarthe, Thomas. De la destruction à la restauration: L'idéologie du royaume d'Oviedo-Leon (VIIT-XI siècles). Turnhout: Brepols, 2003.

DíAz y DíAz, Manuel C. «La circulation des manuscrits dans la Péninsule Ibérique du VIII ${ }^{\mathrm{e}}$ au XI ${ }^{\mathrm{e}}$ siècle». Cahiers de Civilisation Médiévale, 1969, vol. 12, pp. 219-241 y 383-392.

Díaz y Díaz, Manuel C. Códices visigóticos en la monarquía leonesa. León, Centro de Estudios e Investigación San Isidoro, 1983.

Díaz y DíAz, Manuel C. Libros y librerías en la Rioja altomedieval. 2. a ed. Logroño: Instituto de Estudios Riojanos, 1991.

Díaz y Díaz, Manuel C., Moralejo, Serafín, Pardo Gómez, M. a Virtudes y García Piñeiro, M. ${ }^{a}$ Araceli (eds.). Libro de Horas de Fernando I de León. Santiago de Compostela: Xunta de Galicia, 1995, 2 vols.

Durán Gudiol, Antonio. «Francos, pamploneses y mozárabes en la Marca Superior de al-Ándalus». En SÉNAC, Philippe (dir.). La Marche Superieur d'al-Andalus et l'Occident chrétien. Madrid: Casa de Velázquez, 1991, pp. 141-147.

Étaix, Raymond. «Le "Smaragde" de Cordoue et autres manuscrits apparentés». Miscellània Litúrgica Catalana, 1990, vol. 4, pp. 13-27.

Fontaine, Jacques y Pellistrandi, Christine (eds.). L'Europe héritière de l'Espagne wisigothique. Madrid: Casa de Velázquez, 1992.

Gaite Pastor, Jesús y Sáenz Pascual, Raquel. «Psalterio y Libro de Cánticos». En Bango Torviso, Isidro (ed.). La edad de un reyno. Sancho el Mayor y sus herederos. Pamplona: Fundación para la Conservación del Patrimonio Histórico de Navarra, 2006, pp. 128-129.

Galván Fraile, Fernando. "Documento de fundación del monasterio de Santa María de Nájera». En Bango Torviso, Isidro (ed.). La edad de un reyno. Sancho el Mayor y sus herederos. Pamplona: Fundación para la Conservación del Patrimonio Histórico de Navarra, 2006, pp. 287-290.

García de Cortázar y Ruiz de Aguirre, José Ángel. «El dominio del monasterio de San Millán de la Cogolla en los siglos x al xiı». En Cordero Rivera, Juan (coord.). San Millán de la Cogolla. Logrońo: Ateneo Riojano, 1999, pp. 13-26.

García de Cortázar y Ruiz de Aguirre, José Ângel. El dominio del monasterio de San Millán de la Cogolla (siglos X al XIII). Introducción a la historia rural de Castilla altomedieval. Salamanca: Universidad de Salamanca, 1969.

GIL, Juan (ed.). Corpus Scriptorum Muzarabicorum. Madrid: CSIC, Instituto Antonio de Nebrija, 1973, 2 vols. 
FERMÍN MIRANDA GARCÍA

AUTORES CAROLINGIOS EN LOS CÓDICES HISPANOS (SIGLOS IX-XI).

UN ENSAYO DE INTERPRETACIÓN

Goñi Gaztambide, José. Los obispos de Pamplona. I. Siglos IV-XIII. Pamplona: Eunsa-Gobierno de Navarra, 1979.

Gorman, Michael. «The Commentary on Genesis of Claudius of Turin and Biblical Studies under Louis the Pious». Speculum, 1997, vol. 72, pp. 279-329.

GrÉGOIRE, Réginald. «Benedetto di Aniane nella riforma monastica carolingia». Studi Medievali, 1985, s. 3, vol. 26, pp. 573-610.

Jimeno, Roldán y Pescador, Aitor. Colección documental de Sancho Garcés III, el Mayor, rey de Pamplona (1004-1035). Pamplona: Pamiela, 2003.

LaCARra, José María. «Textos navarros del Códice de Roda». Estudios de Edad Media de la Corona de Aragón, 1945, vol. 1, pp. 196-198.

Lara Olmo, Juan Carlos. «El relato del traslado de los santos mártires Jorge, Aurelio y Natalia: un valioso escrito hagiográfico y documental histórico de mediados del siglo IX». Hispania Sacra, 1999, vol. 51, pp. 55-89.

Larrea, Juan José. "Construir un reino en la periferia de Al-Ándalus: Pamplona y el Pirineo Occidental en los siglos viII y IX». Territorio, Sociedad y Poder, 2009, Anejo 2, pp. 287-288.

LARreA, Juan José. «Obispos efímeros, comunidades y homicidio en la Rioja Alta en los siglos x y XI». Brocar, 2007, vol. 31, pp. 177-200.

Linage Conde, Antonio. Los orígenes del monacato benedictino en la Peninsula Ibérica. León: Centro de Estudios e Investigación San Isidoro, 1973, 3 vols.

López Pereira, J. Eduardo (ed.). Crónica mozárabe de 754. Zaragoza: Anubar, 1980, $\$ 80$.

Martín Duque, Ángel. «Del espejo ajeno a la memoria propia». En Martín DuQue, Ángel (dir.). Signos de identidad histórica para Navarra. Pamplona: Caja de Ahorros de Navarra, 1996, pp. 21-50.

Martín DuQue, Ángel. «El despliegue del reino de Aragón y Pamplona (1076-1134)». En Historia de España Menéndez Pidal. IX. Madrid: Espasa-Calpe, 1998, pp. 279-323.

Martín Duque, Ángel. «El reino de Pamplona». En Historia de España Menéndez Pidal. VII**. La España de los siglos VIII al XI. Los núcleos pirenaicos (718-1035). Navarra, Aragón, Cataluña. Madrid: Espasa-Calpe, 1999, pp. 41-266.

Martín Duque, Ángel. Sancho III el Mayor de Pamplona. El rey y su reino (1004-1035). Pamplona: Gobierno de Navarra, 2007.

Martínez Gázquez, José y Puigvert y Planaguma, Gemma. "Los excerpta de Beda (De temporum ratione, 19 y 23) en Ripoll (ACA, Ripoll 59 y Vat. reg. lat. 123)». Emerita. Revista de Lingüistica y Filología, 1996, vol. 62, pp. 295-305.

Millares Carlo, Agustín. Corpus de códices visigóticos (ed. de M. C. Díaz, A. M. Mundó, J. M. Ruiz Asencio, B. Casado y E. Lecuona). Las Palmas de Gran Canaria: UNED, 1999, 2 vols.

Miranda García, Fermín. «Carlomagno, los carolingios y la creación de la Marca Hispánica». En Peña González, José y Rodríguez de la Peña, Manuel Alejandro (eds.). Carlomagno y la civilización carolingia. Madrid: CEU Ediciones, 2014, pp. 165-194.

Miranda García, Fermín. "La imagen del poder monárquico en el reino de Pamplona (siglo x)». En VI Congreso General de Historia de Navarra. Navarra: memoria e imagen. III. Ponencias. Pamplona: Ed. Eunate, 2007, pp. 73-95.

Miranda García, Fermín. "Monarquía y espacios de poder político en el reino de Pamplona (1000-1035)». En XXX Semana de Estudios Medievales de Estella'03. Ante el milenario del reinado de Sancho el Mayor. Un rey navarro para España y Europa. Pamplona: Gobierno de Navarra, 2004, pp. 43-70.

Mundó, Anscari M. «Entorn de dos codex del segle x è de San Cugat del Vallès». Faventia, 1982, vol. 4, n. ${ }^{\circ}$ 2, pp. 7-24. 


\author{
FERMÍN MIRANDA GARCÍA \\ AUTORES CAROLINGIOS EN LOS CÓDICES HISPANOS (SIGLOS IX-XI). \\ UN ENSAYO DE INTERPRETACIÓN
}

Mundó, Anscari. «Importación, exportación y expoliación de códices en Cataluña (siglos viII al XIII)", pp. 87-134. En Coloquio sobre circulación de códices y escritos entre Europa y la Península en los siglos VIII-XIII (1982. Santiago de Compostela). Santiago de Compostela: Universidad de Santiago de Compostela, 1988.

Mundó, Anscari. «L'escriptori i la biblioteca de Ripoll des de la fundació fins el segle XI». En Obres completes. 1. Catalunya de la romanitat a la sobirania. Barcelona: Curial Edicions, 1998, pp. 434-437.

Muñız López, Iván. «Hacia una arqueología de la cultura. Patrones de movilidad intelectual entre Asturias y Francia (siglos v-XIII d. C.)». Revista de Literatura Medieval, 2013, vol. 25, pp. 165-194.

Noble, Thomas F. X. Charlemagne and Louis the Pious. The Lives by Einhard, Notker, Ernoldus, Thegan and the Astronomer. University Park: Pennsylvania State Press, 2009.

Olivar, Alexander. Catàleg dels manuscrits de la biblioteca del monestir de Montserrat. Montserrat: Monestir de Monserrat, 1977.

OrLANDis, José. «La circunstancia histórica del adopcionismo español», Scripta Theologica, 1994, vol. 26, pp. 1079-1091.

Otтen, Willemien. "Carolingian theology». En Evans, G. R. (ed.). The medieval teologians. An Introduction to Theology in the Medieval Period. Oxford: Blackwell, 2000, pp. 65-82.

Paolo Diacono, Vita sancti Gregorii Magni, ed. S. Tuzzo. Pisa: Centro di Cultura Medievale, 2002.

Pardo Gómez, M. ${ }^{a}$ Virtudes. Catálogo de manuscritos da Biblioteca Xeral. Santiago de Compostela: Universidade de Santiago de Compostela, 1998.

Ponesse, Matthew D. «Editorial practice in Smaragdus of St Mihiel's commentary on the Rule of St Benedict». Early Medieval Europe, 2010, vol. 18, pp. 61-91.

Ponesse, Matthew D. "Smaragdus of St Mihiel and the Carolingian monastic reform». Revue Bénédictine, 2006, vol. 116, pp. 367-392.

Puig, Ignasi M. y Giner, M. Assumpta. Index codicològic del Viaje Literario de Jaume Villanueva. Barcelona: Institut d'Estudis Catalans, 1998.

Rıu, Manuel. «La organización eclesiástica». En Historia de España Menéndez Pidal. VII**. La España de los siglos VIII al XI. Los núcleos pirenaicos (718-1035). Navarra, Aragón, Cataluña. Madrid: Espasa-Calpe, 1999, pp. 613-648.

Riu, Manuel. «La vida cultural». En Historia de España Menéndez Pidal. VII**. La España de los siglos VIII al XI. Los núcleos pirenaicos (718-1035). Navarra, Aragón, Cataluña. Madrid: Espasa-Calpe, 1999, pp. 699-725.

Rodríguez de la Peña, Manuel Alejandro. Los reyes sabios. Cultura y poder en la Antigüedad Tardía y Alta Edad Media. San Sebastián de los Reyes: Actas, 2008.

Ruiz Asencio, José Manuel. «Códices pirenaicos y riojanos en la biblioteca de Silos en el siglo XI». En Fernández Flórez, José A. (dir.). Silos. Un milenio. Actas del Congreso Internacional sobre la Abadia de Santo Domingo de Silos. II. Historia. Santo Domingo de Silos: Universidad de Burgos-Abadía de Silos, 2003, pp. 177-210.

Ruiz Asencio, José Manuel. «Libellus a regula Sancti Benedicti Subtractus. Bibl. Academia de la Historia, Emilianensis, 62». En García Turza, Claudio (coord.). Los manuscritos visigóticos: Estudios paleográfico y codicológico. I. Códices riojanos datados. Logroño: Fundación San Millán de la Cogolla, 2002, pp. 175-200.

Ruiz García, Elisa. «Arma regis. Los libros de Fernando I y doña Sancha». Lemir. Revista de Literatura Española Medieval y del Renacimiento, 2014, vol. 18, pp. 137-176.

Ruiz García, Elisa. Catálogo de la sección de códices de la Real Academia de la Historia. Madrid: Real Academia de la Historia, 1997. 
FERMÍN MIRANDA GARCÍA

AUTORES CAROLINGIOS EN LOS CÓDICES HISPANOS (SIGLOS IX-XI).

UN ENSAYO DE INTERPRETACIÓN

Salrach, Josep M. ${ }^{a}$. «El régimen político condal». En Historia de España Menéndez Pidal. VII**. La España de los siglos VIII al XI. Los núcleos pirenaicos (718-1035). Navarra, Aragón, Cataluña. Madrid: Espasa-Calpe, 1999, pp. 575-612.

Silva y Verástegui, Soledad de. «La imagen miniada». En Bango Torviso, Isidro (ed.). La edad de un reyno. Sancho el Mayor y sus herederos. Pamplona: Fundación para la Conservación del Patrimonio Histórico de Navarra, 2006, pp. 409-411.

Sirantoine, Hélène. Imperator Hispanie. Les idéologies impériales dans le royaume de Léon (IXe-XII siècles). Madrid: Casa de Velázquez, 2012.

Smaragde de Saint-Miniel. Commentaire du Prologue à la Règle de saint Benoît, eds. y trads. P. Engelbert, A. Spannegel y J.-É. Stroobant de Saint-Éloy. Paris: Éditions du Cerf, 2006.

Smaragdi abbatis monasterii Sancti Michaelis Virdunensis opera omnia, ed. J. P. Migne. Turnouth: Brepols, 1997.

Smaragdus of Saint-Miniel. The Crown of Monks, ed. y trad. D. Barry. Trappist (KY): Cistercian Publications, 2013.

Tyson, Moses. The Spanish manuscripts in the John Rylands Library. Manchester: Manchester University Press, 1932.

Ubieto Arteta, Antonio. Cartulario de San Millán de la Cogolla (759-1076). Valencia: Anubar, 1976.

Ubieto Arteta, Antonio. Cartulario de Siresa. Valencia: Anubar, 1960.

Ubieto Arteta, Antonio. Historia de Aragón. 6. Orígenes de Aragón. Zaragoza: Anubar, 1989, pp. 355-375.

Udina, Federico. «Cataluña». En Historia de España Menéndez Pidal. IX. Madrid: Espasa-Calpe, 1998 , pp. 425-402.

Villanueva, Jaime. Viage literario a las Iglesias de España. Madrid: Real Academia de la Historia, 1806-1807, vol. 8, pp. 36-37.

Walker, G. S. M. Sancti Columbani Opera. Dublin: The Dublin Institute for Advanced Studies, 1957.

ZAPke, Susana (ed.). Hispania vetus. Manuscritos litúrgicos-musicales. De los orígenes a la transición francorromana: siglos IX-XII. Bilbao: Fundación BBVA, 2007.

Zimmermann, Michel. Écrire et lire à Catalogne (XTe-XIT siècles). Madrid: Casa de Velázquez, 2003. 